\title{
Spatiotemporal Analysis of Spread of Infections by Verticillium dahliae Pathotypes Within a High Tree Density Olive Orchard in Southern Spain
}

\author{
J. A. Navas-Cortés, B. B. Landa, J. Mercado-Blanco, J. L. Trapero-Casas, D. Rodríguez-Jurado, and R. M. Jiménez-Díaz
}

First, third, fourth, and fifth authors: Instituto de Agricultura Sostenible (IAS), Consejo Superior de Investigaciones Científicas (CSIC), Apartado 4084, 14080 Córdoba, Spain; second and sixth authors: IAS-CSIC and Escuela Técnica Superior de Ingenieros Agrónomos y Montes (ETSIAM), Universidad de Córdoba (UCO), Edificio C4-Celestino Mutis, Campus de Rabanales, Ctra. Madrid- Cádiz, km 396, 14071 Córdoba, Spain.

Current address of B. B. Landa: IAS-CSIC.

Current address of D. Rodríguez-Jurado: Laboratorio de Patología Vegetal, CIFA Alameda del Obispo, IFAPA, Junta de Andalucía, Apartado 3092, 14080 Córdoba, Spain.

Accepted for publication 9 April 2007.

\begin{abstract}
Navas-Cortés, J. A., Landa, B. B., Mercado-Blanco, J., Trapero-Casas, J. L., Rodríguez-Jurado, D., and Jiménez-Díaz, R. M. 2008. Spatiotemporal analysis of spread of infections by Verticillium dahliae pathotypes within a high tree density olive orchard in southern Spain. Phytopathology 98:167-180.

The development of Verticillium wilt epidemics in olive cv. Arbequina was studied from November 1999 to May 2003 in a drip-irrigated, nontillage orchard established in a soil without a history of the disease at Córdoba, southern Spain. Disease incidence measured at 1-month-intervals increased from 0.2 to $7.8 \%$ during this period. Verticillium dahliae infecting the trees was characterized as defoliating (D) or nondefoliating (ND) pathotypes by a specific, multiplex-polymerase chain reaction (PCR) assay. Of the symptomatic trees, 87.2 and $12.8 \%$ were infected by the D or ND pathotypes, respectively. Dynamics of disease incidence were described by a generalized logistic model with a multiple sigmoid pattern. In the fitted model, the infection rate was highest in the winter to spring period and decreased to minimum values in the summer to fall period. Binary data of disease incidence was analyzed for point pattern

domness of disease within rows. The binomial index of dispersion, interclass correlation, and Taylor's power law for various quadrat sizes suggested aggregation of diseased trees within the quadrat sizes tested. Spatial analysis by distance indices showed a nonrandom arrangement of quadrats containing infected trees. Spatial pattern was characterized by the occurrence of several clusters of infected trees. Increasing clustering over time was generally suggested by stronger values of clustering index over time and by the increase in the size of patch clusters. Significant spatial association was found in the clustering of diseased trees over time across cropping seasons; however, clustering was significant only for infections by $\mathrm{D} V$. dahliae, indicating that infections by the $\mathrm{D}$ pathotype were aggregated around initial infections. The number and size of clusters of D V. dahliae-infected trees increased over time. Microsatellite-primed PCR assays of a representative number of $V$. dahliae isolates from diseased trees indicated that the majority of infecting D isolates shared the fingerprinting profile with D $V$. dahliae isolated from soil of a naturally infested cotton field in close proximity to the orchard, suggesting that short distance dispersal of the pathogen from this soil to the olive orchard may have occurred.
\end{abstract} and spatial correlation, either directly or after parsing them in contiguous quadrats. Overall, ordinary runs analysis indicated a departure from ran-

Knowledge of the spatiotemporal pattern and spread of plant diseases (i.e., the arrangement of diseased plants relative to each other on a time basis [14]) in susceptible crops may provide valuable information about the nature and role of inoculum sources for development of epidemics, and thus contribute to designing adequate strategies for plant disease management. This knowledge may be particularly relevant for Verticillium wilt of olive (Olea europaea L.) in southern Spain, caused by the soilborne fungus Verticillium dahliae Kleb., because of the increasing importance and distribution of the disease and occurrence of a highly virulent defoliating (D) $V$. dahliae pathotype in irrigated olive orchards during the last decade $(23,33,42)$.

Verticillium wilt affects olive throughout its range of cultivation (23), causing severe yield losses and tree mortality (26). In Spain,

Corresponding author: J. A. Navas-Cortés; E-mail address: jnavas@ias.csic.es

* The $e$-Xtra logo stands for "electronic extra" and indicates that Figures 1 and 6 appear in color online.

doi:10.1094/PHYTO-98-2-0167

(C) 2008 The American Phytopathological Society
Additional keywords: Olea europaea. the disease was first reported in experimental fields near Córdoba, Andalusia, southern Spain in 1980, and during the last 20 years it has spread throughout that area as well as to other regions in Spain $(6,40,42)$. Several factors might have accounted for the increasing spread of the disease, such as new olive orchards being established in irrigated soils infested by the pathogen or close to other $V$. dahliae-infected crops, such as cotton, and/or the use of $V$. dahliae-infected olive planting material $(40,42,47)$.

Severity of attacks by $V$. dahliae on olive strongly depends on virulence of the pathogen isolates (here defined as the amount of disease caused in a host genotype). $V$. dahliae isolates infecting olive can be classified into defoliating (D) or nondefoliating (ND) pathotypes, based on their ability to cause defoliation or no defoliation of green leaves from shoots and twigs $(28,40)$. These two pathotypes can be differentiated in infected plants by means of specific polymerase chain reaction (PCR) markers (33). Infections by the $\mathrm{D}$ pathotype can be lethal to the plant, whereas olive trees infected by the ND pathotype eventually can show complete remission from symptoms $(23,33,40)$. Differential virulence of $V$. dahliae isolates also occurs in upland cotton (Gossypium hirsutum L.), with isolates from cotton and olive showing 
cross-virulence $(40,43)$. In Spain, the D pathotype was first reported infecting cotton in a restricted area of intensive cultivation at the southern part of Andalusia in 1981 (2). This pathotype has now appeared to distant cotton- and olive-growing areas all over Andalusia (8), but has not yet been reported in other olive growing areas in northern Spain or other countries in the Mediterranean Basin, except Greece (11) and Israel (25).
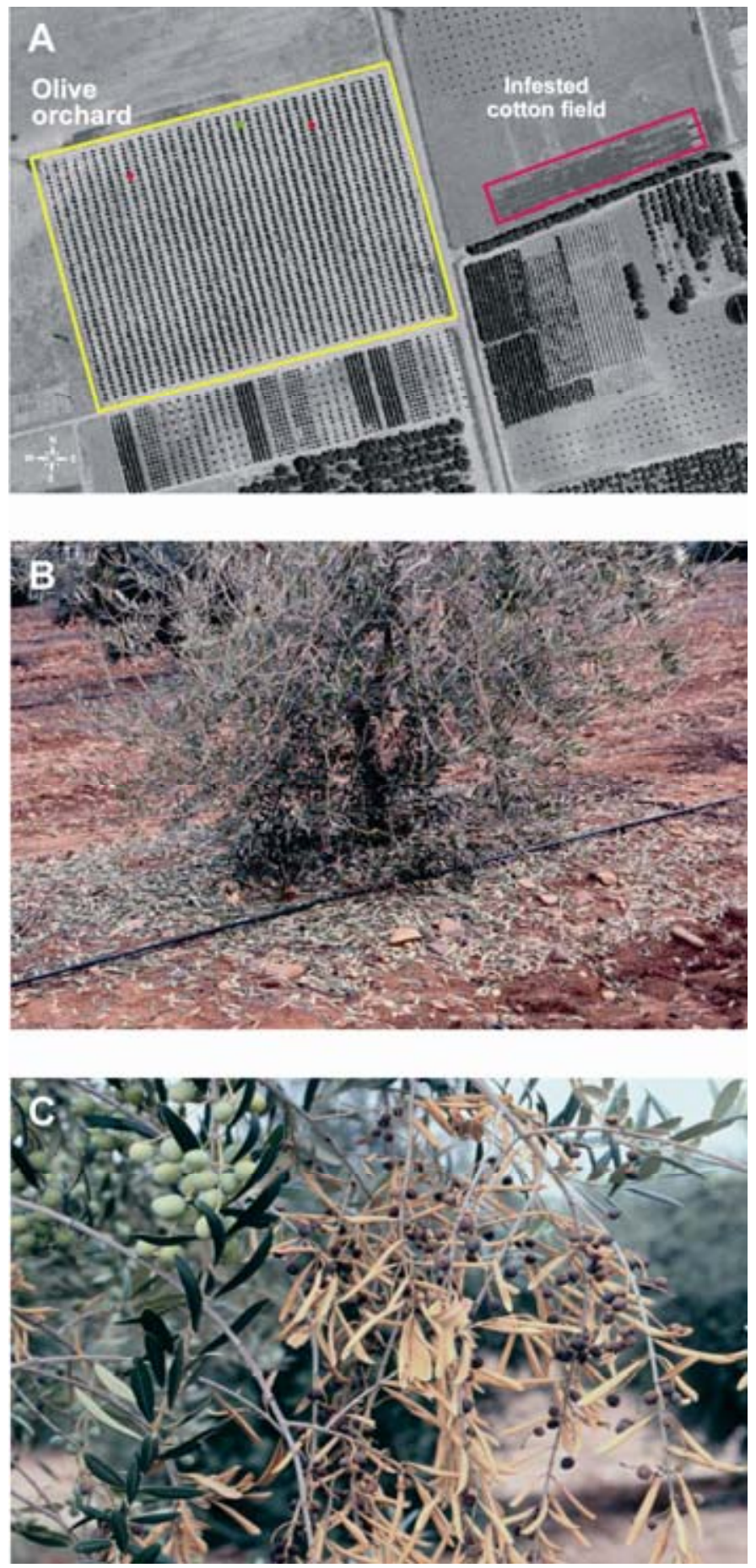

Fig. 1. A, Aerial overview of the olive orchard used in the study. Dots indicate olive trees that were first diseased by November 1999 and infected by either the defoliating ( $\mathrm{D}$, circles) or nondefoliating ( $\mathrm{ND}$, triangle) Verticillium dahliae pathotypes. B, Symptoms associated with infections by D V. dahliae. Note the intense defoliation of diseased trees and large number of fallen green leaves. C, Symptoms associated with infections by ND V. dahliae. Note olive branches with dried, necrotic leaves that remain attached to the symptomatic branch.
Little is known about the epidemiology of Verticillium wilt of olive caused by $\mathrm{D}$ or ND V. dahliae pathotypes. In Córdoba, southern Spain, disease in 1-year-old olive plants of highly susceptible cv. Picual developed earlier and faster for the D pathotype compared with the ND pathotype (27). In Israel, Verticillium wilt developed from mid winter to the end of spring, with disease incidence and severity decreasing during summer and fall, in 4-year-old 'Picual' olives irrigated with saline water and presumably infected by the ND pathotype (26). Dispersal of pathogen propagules may occur with the movement of infested soil by furrow and flood irrigation (48), machinery and wind (10), or V. dahliae-infected olive leaves $(41,49,50)$ and plant refuse from $V$. dahliae-infected cotton on olive crops (43). Dispersion of $V$. dahliae in infected leaves may be of particular importance for D $V$. dahliae because infections by this pathotype induce extensive and early drop of infected green leaves $(23,41)$. Leaves from D or ND $V$. dahliae-infected olive trees may harbor the pathogen and contribute to increase the number of microsclerotia in soil $(41,49,50)$

Description of the spatiotemporal characteristics of Verticillium wilt epidemics in olive may provide valuable information on pathogen dissemination and epidemic progress, but these studies are lacking both for the D and ND $V$. dahliae pathotypes on olives. Several methods are available for the description of spatial disease patterns that fall into two general classes: point-pattern (31) and correlation-based analyses $(32,38,53,54)$, which quantify spatial pattern on different scales (i.e., within and between quadrats) (31). The combination of such methods provides efficient tools for epidemic quantification and examines epidemics at multiple spatial scales $(16,31)$. It has been proved that this method can successfully describe epidemics in several pathosystems $(1,9,37,44)$ but it has not been used for the study of Verticillium wilts in woody crops.

While conducting an experiment on the efficiency of water use in a high-plant density olive orchard at Córdoba, southern Spain, newly developed $V$. dahliae infections were observed in three trees in close mutual proximity,with subsequent disease spread within the orchard. This olive orchard was established in a field site that did not have a history of susceptible crops to, or a record of, Verticillium wilt. The aim of this study was to examine the temporal, spatial, and spatiotemporal dynamics of Verticillium wilt in this orchard and to assess the effect of $V$. dahliae pathotypes on the spatiotemporal dynamics of Verticillium wilt epidemics in olive.

\section{MATERIALS AND METHODS}

Experimental site. The study was done in a 4.6-ha flat, uniform plot of sandy loam soil, located at the IFAPA Alameda del Obispo Agricultural Research Station, Córdoba, southern Spain $\left(37.5^{\circ} \mathrm{N}, 4.8^{\circ} \mathrm{W}\right.$, altitude $\left.110 \mathrm{~m}\right)$ from 1999 to 2003 (Fig. 1A). To the best of our knowledge, the plot had not been planted to $V$. dahliae-susceptible crops and had no history of Verticillium wilt in the 15 years previous to olive plantation. The trees were established on July 1997 with nursery-propagated 1-year-old olive plants (cv. Arbequina) on their own roots, at a spacing of $3.5 \mathrm{~m} \times$ $7 \mathrm{~m}$ (408 trees per hectare) which is a commonly used density for modern intensive olive plantations in the area of the study. 'Arbequina' olives are extremely susceptible and susceptible to D and ND V. dahliae, respectively, under controlled conditions (28). The orchard was drip irrigated (two drippers per tree located 10 to $20 \mathrm{~cm}$ apart from the trunk) to fully satisfy tree water demand. The orchard was managed using no-tillage practices and weed control was achieved with glyphosate herbicide treatments between rows.

Disease assessment and isolation of $V$. dahliae from symptomatic plants and soil. Incidence of Verticillium wilt (percentage of diseased trees) in the orchard was determined at 1-month- 
intervals by visual observation of symptoms on trees along the rows throughout the entire plot. The location of each diseased tree was mapped on a column-row diagram every assessment date. Infections by $V$. dahliae were confirmed by means of isolations using four stem fragments sampled from each of four young symptomatic branches per symptomatic tree. Tissues were washed under running tap water, then surface disinfested in $0.5 \%$ $\mathrm{NaOCl}$ for $2 \mathrm{~min}$ and dried between sterile filter paper. Pieces, 5 to $10 \mathrm{~mm}$ long of disinfested tissues were plated onto water agar amended with aureomycin (1 liter of distilled water, $20 \mathrm{~g}$ of agar, $30 \mathrm{mg}$ of aureomycin) and were incubated at $25^{\circ} \mathrm{C}$ in the dark for 7 days. Pure cultures of isolates were further used for the molecular pathotyping of $V$. dahliae isolates. The identification of $V$. dahliae isolates was determined based on morphology of conidiophores and microsclerotia formed on plum lactose yeast extract agar (45).

In addition, soil of a field plot located approximately $100 \mathrm{~m}$ away from the 'Arbequina' orchard (Fig. 1A) was sampled and five $V$. dahliae isolates were obtained using the wet sieving method (46). This field plot was frequently cropped to cotton until 1997 for studies on the epidemiology and control of cotton Verticillium wilt, and D $V$. dahliae has become more prevalent in soil relative to the ND pathotype throughout the years of cotton cultivation (J. Bejarano-Alcázar, personal communication).

Molecular pathotyping and genetic variability of $\mathrm{V}$. dahliae isolates. Mycelia for DNA extraction were obtained from colonies of $V$. dahliae isolates actively growing on a film of sterile cellophane layered over a plate of fresh potato dextrose agar (PDA) (250 g of unpeeled potatoes, $20 \mathrm{~g}$ of agar, and $20 \mathrm{~g}$ of glucose per liter of distilled water) and incubating for 5 days at $25^{\circ} \mathrm{C}$ with a 12-h photoperiod of fluorescent and near-UV light at $36 \mu \mathrm{E} \cdot \mathrm{m}^{-2} \cdot \mathrm{s}^{-1}$. Mycelia growing on the cellophane surface were harvested, lyophilized, and stored at $-20^{\circ} \mathrm{C}$. DNA of the isolates was purified using the DNeasy Plant mini Kit (Qiagen, Hilden, Germany). The extracted DNA was checked for quality on agarose gel, quantified using the Quant-iT DNA Broad Range fluorometric assay kit (Molecular Probes, Inc., Leiden, The Netherlands) and a Tecan Safire fluorospectrometer (Tecan Spain, Barcelona, Spain) according to manufacturer's instructions, and diluted in sterile water to a final concentration of 25 to $50 \mathrm{ng} / \mu \mathrm{l}$.

$V$. dahliae isolates were further characterized to species and pathotype by multiplex PCR assay using three primers, DB19/ DB22/espdef01 (33). The use of these three primers in a single PCR assay yields a polymorphic amplicon of 539 or 523 bp which are specific to $V$. dahliae and differentially associated with D and ND V. dahliae, respectively. PCR amplifications and gel electrophoresis were conducted as described previously (33).

A sample of approximately $50 \%$ of the total $V$. dahliae isolates obtained during the study was used to determine the genetic variability within populations of $V$. dahliae $\mathrm{D}$ and ND isolates infecting olive in the orchard by means of microsatellite-primed PCR (MP-PCR) assays. The sampled isolates were representative of those obtained from the 141 infected trees distributed across the orchard during the years of study. MP-PCR assays were done as described by Ma et al. (29) using the M13 repetitive core sequence ( $5^{\prime}$-GAGGGTGGCGGTTCT-3'). The reaction mixture ( $25 \mu$ l total volume) consisted of $20 \mathrm{ng}$ of fungal genomic template, $1.0 \mu \mathrm{M}$ each microsatellite primer, $0.2 \mathrm{mM}$ each dNTP, $2.0 \mathrm{mM} \mathrm{MgCl} 2,1 \times$ Ecogen Taq polymerase buffer $(166 \mathrm{mM}$ $\left[\mathrm{NH}_{4}\right]_{2} \mathrm{SO}_{4}, 670 \mathrm{mM}$ Tris- $\mathrm{HCl}, \mathrm{pH} 8.8,0.1 \%$ Tween-20) and 0.75 units of EcoTaq polymerase (Ecogen, S.R.L., Barcelona, Spain). The following PCR run parameters were used: an initial preheat for $3 \mathrm{~min}$ at $95^{\circ} \mathrm{C}$, followed by 35 cycles of denaturation at $94^{\circ} \mathrm{C}$ for $1 \mathrm{~min}$, annealing at $50^{\circ} \mathrm{C}$ for $1 \mathrm{~min}$, and extension at $72^{\circ} \mathrm{C}$ for $1.5 \mathrm{~min}$, with a final extension at $72^{\circ} \mathrm{C}$ for $10 \mathrm{~min}$.

All PCR assays were performed with an iCycler thermal cycler (BioRad, Madrid, Spain). Amplification products were separated by electrophoresis in $1.5 \%$ TAE buffer for $5 \mathrm{~h}$ at $80 \mathrm{~V}$, stained with ethidium bromide, visualized, and photographed under UV light. Reactions were repeated twice and always included negative controls (no DNA) and positive controls (template DNA from mycelia of cotton $V$. dahliae isolates representative of the ND [isolate V-176I] and D [isolate V-138I] pathotypes [2]). MP-PCR patterns were digitalized, converted, and normalized with 1-kb gene-ruler DNA ladder (Fermentas, St Leon-Rot, Germany), and compared with Bionumerics 4.5 software (Applied Maths, Kortrijk, Belgium). A band-matching algorithm (band-matching tolerance of $0.75 \%$ ) was selected to calculate pair-wise similarity matrices with the Dice coefficient. Cluster analysis of similarity matrices was performed by the unweighted pair group method using arithmetic averages (UPGMA).

Temporal analysis. A generalized logistic model of multiple sigmoid pattern was fitted to the observed disease incidence progress data, as described by Hau et al. (19). Time, measured in days after first symptoms appearance, was used as the independent variable. In this model, we assumed that the multiple sigmoid curve is the result of four consecutive and overlapping growth processes. Then, the curves can be approximated by the sum of four simple growth functions, one for each crop season. For the logistic equation, the sum is given by

\section{$y_{\mathrm{L}}(t)=p_{11} /\left\{1+\exp \left[-\left(p_{12}+p_{13} t\right)\right]\right\}+p_{21} /\left\{1+\exp \left[-\left(p_{22}+p_{23} t\right)\right]\right\}+$ $p_{31} /\left\{1+\exp \left[-\left(p_{32}+p_{33} t\right)\right]\right\}+p_{41} /\left\{1+\exp \left[-\left(p_{42}+p_{43} t\right)\right]\right\}$}

This combined equation has three parameters for each of the four phases. The parameters $p_{11}, p_{21}, p_{31}, p_{41}$ are the upper asymptotes, $p_{12}, p_{22}, p_{32}, p_{42}$ are related to the initial level of disease, and $p_{13}, p_{23}, p_{33}, p_{43}$ are the rate of each of the four phases equivalent to each of the four cropping seasons in the study (19). Regression analyses were conducted using the least-squares program for nonlinear models procedure of SPSS Software (version 12.0; SPSS Inc., Chicago, IL). The coefficient of determination $\left(R^{2}\right)$, the mean square error, standard errors associated with the parameter estimates, confidence intervals of predicted values, and the pattern of the standardized residuals plotted against either predicted values or the independent variable were used to evaluate the appropriateness of the model to describe the data.

Spatial pattern analyses. Spatial maps of Verticillium wilt incidence at each assessment date were obtained using binary data by performing a semivariance analysis that was followed by a kriging of the data by the block method using GS + 7.0 (Gamma Design Software LLC, Plainwell, MI).

Analyses of spatial pattern were performed at three levels of spatial scale as described elsewhere $(1,9,37,44)$.

Correlation-based spatial analyses. For the first level of spatial scale, the occurrence of aggregation between adjacent diseased trees was determined using ordinary runs analyses, a unidirectional test that assess aggregation within columns or rows in a population matrix of diseased plants (31). Analyses were performed using disease incidence data collected on individual trees at each assessment date. The percentage of rows with aggregated patterns of disease was calculated (32). The level of significance was determined using a standard $Z$ test statistic to compare the number of runs observed with the number of runs expected under a null hypothesis of randomness. A number of observed runs significantly lower than the expected number of runs under the hypothesis of randomness were considered as an indication of spatial aggregation (32).

Point-pattern spatial analyses. For the second level of spatial scale, data were examined for the occurrence of aggregation at various quadrat sizes. The average of these quadrat counts provides information on the incidence of disease, as well as on the variation of disease incidence data of these quadrat counts (21, 22). Disease incidence data for each assessment date were partitioned into quadrats of $2(2 \times 1), 4(2 \times 2), 8(2 \times 4)$, and 16 $(4 \times 4)$ olive trees. When data are expressed as disease incidence, 
the beta-binomial distribution can be used to determine the occurrence of aggregation (22,31). Randomness between quadrats was thus assessed via beta-binomial analysis, which regards the probability of a plant being diseased as a beta-distributed variable (22). The beta-binomial index of dispersion $\left(I_{\beta}\right)$ was used to test for within-quadrat randomness of Verticillium wilt-diseased trees at each quadrat size (31). $I_{\beta}$ is defined as the ratio of the observed variance $\left(v_{\text {obs }}\right)$ to the expected binomial variance $\left(v_{\text {bin }}\right)$ for a random distribution of binary data (31). For the beta-binomial index, a large index of dispersion $\left(I_{\beta}>1\right)$ combined with a small probability $(P<0.05)$ suggests aggregation of symptomatic plants (31). The $C(\alpha)$ test was used to test for the null hypothesis of randomness with the alternative hypothesis of over dispersion described by the beta-binomial distribution $(22,30)$. The beta-binomial and binomial distributions were fitted to disease incidence data for each assessment date using the computer program BBD (30). Randomness within quadrat was also assessed by the interclass correlation $(k)$, which measures the tendency of the plants within a sampling quadrat to have a similar disease status. $k$ is related to the index of dispersion $\left(I_{\beta}\right)$ by $k=\left(I_{\beta}-1\right) /(n-1)$, where $n$ is the quadrat size (13). When the value of $k$ value is close to zero, the beta-binomial distribution approaches the binomial distribution, which is indicative of a random spatial arrangement. Conversely, as the value of $k$ increases, spatial aggregation also increases (13).

The binary form of Taylor's power law was used as an assessment of over dispersion across all disease assessment dates and allowed us to determine if the degree of heterogeneity was related to disease incidence. The binary power law (21) relates the observed variance of diseased trees within quadrats $\left(v_{\mathrm{obs}}\right)$ to the expected binomial variance $\left(v_{\text {bin }}\right)$. In this case, $\log \left(v_{\text {obs }}\right)=\log (A)+$ $b \log \left(v_{\text {bin }}\right)$, in which $\log (A)$ and $b$ are the intercept and the slope of the regression line, respectively. A random spatial pattern is suggested when both $A$ and $b$ are equal to 1 . Conversely, a constant level of aggregation occurs for all the incidence values when $b=1$ and $\log (A)>1$. When $b>1$, the degree of aggregation varies according to incidence. The parameters $\log (A)$ and $b$ were estimated by linear regression using the least squares method, and the significance of the relationship between $\log \left(v_{\mathrm{obs}}\right)$ and $\log \left(v_{\text {bin }}\right)$ was determined by the $F$ test. The equality of parameters $b$ and $A$ to unit was assessed by the $t$ test using the estimate of the parameter and its standard deviation.

SADIE. In the third level of spatial scale, the strength and directionality or orientation of aggregation among quadrats containing Verticillium wilt-diseased olive trees were examined with spatial analysis by distance indices (SADIE) as described by Perry et al. (36). Although SADIE is a correlation-based spatial analysis, it also takes into account the inherent heterogeneity within the dataset like those in the point-pattern based methods. Similarly to the analyses described above, SADIE analysis was applied to the total Verticillium wilt incidence, as well as to disease incidence induced by either D or ND V. dahliae separately. Descriptions of SADIE analyses have been presented previously $(36,53,54)$. Briefly, the SADIE analysis uses the coordinates (location) of the quadrats and the counts of individuals (i.e., diseased trees) per quadrat to quantify the spatial pattern in the sampled population. This is done by measuring the minimum total effort that individuals must expend to reach arrangements in which individuals are spaced as regularly as possible. This effort is represented by the distance to regularity $\left(D_{r}\right)$ and its associated probability $P_{a}$ (proportion of randomized samples with distance to regularity as large as, or larger than, the observed value of $D_{r}$ ). The degree of nonrandomness is quantified by comparing the observed spatial pattern with rearrangements obtained after random permutations of the individuals among the quadrats. An overall index of aggregation $\left(I_{a}\right)$ is given by $I_{a}=D_{r} / E_{a}$, where $E_{a}$ is equal to the mean distance to regularity of the randomized samples. Patterns of aggregation are indicated by $I_{a}$ values: aggre- gated if $I_{a}>1$, spatially random if $I_{a}=1$, and regular if $I_{a}<1$. The red-blue extension of SADIE was used to measure and map the degree of pattern locally (36). The organization of clusters into patches (neighborhoods of units with counts larger than the average density of $m$ ) or gaps (neighborhoods of units with counts of $<m$ ) can be analyzed by computing a dimensionless index of clustering from randomizations for each sampling unit (quadrat) (36). The index $v_{i}$ measures the degree to which the unit contributes to a patch, whereas $v_{j}$ is defined similarly but for a gap and takes by convention a negative value. As a rule, values of $v_{i}$ larger than 1.5 and those of $v_{j}$ smaller than -1.5 indicate units as members of a patch or a gap, respectively (1.5 times the expected values of $v_{i}=1$ or $v_{j}=-1$ for random arrangements). Maps and contour plots were drawn from those values. Each map was parsed into quadrats and the number of patch and gap clusters, their location, and their size for each assessment date were analyzed using SADIE software (Rothamsted Research Institute, Rothamsted, UK) (36). A total of 5,967 randomizations were performed for each individual analysis.

Spatiotemporal analysis. The spatial association between pairs of time periods was analyzed using SADIE as described by Winder et al. (51). Local association was investigated using the index $X_{k}$ based on the similarity between clustering indices of two given time periods. Overall spatial association $X_{k}$ was calculated as the mean of individual local values. Significance of $X_{k}$ was tested by randomizations, with cluster indices reassigned amongst the quadrats after allowance for small-scale spatial autocorrelation in the cluster indices from either population (51). The maximum number of 9,999 randomizations was performed and a two-tailed test was used to assess significance. For this test, a null hypothesis of no association was used (51). Local association was calculated for each of the six possible combinations of pairs of consecutive crop seasons over the period of the study from the year 1999 to 2003. In addition, the association between the spatial pattern of incidences of infections of olive trees by the D or ND $V$. dahliae pathotypes was determined for each cropping season.

\section{RESULTS}

Verticillium wilt symptoms development and dynamic of epidemics. Percentage of positive isolation of $V$. dahliae from symptomatic trees ranged from 8 to $100 \%$, being characterized to pathotype by a multiplex PCR assay in all cases. Both infections by D or ND $V$. dahliae pathotypes occurred in 'Arbequina' olive trees in the orchard of the study. Only three trees were symptomatic in November 1999, equivalent to $0.17 \%$ disease incidence. These trees were close to each other and located at the north-central zone of the orchard (Fig. 1A). Over time, diseased trees subsequently appeared distributed across the entire orchard reaching a total number of 141 ( $7.83 \%$ disease incidence) by July 2003. Of the diseased trees, $123(87.2 \%)$ and 18 (12.8\%) were infected by D or ND V. dahliae, respectively. Only one pathotype was found infecting a given symptomatic olive tree. Symptoms in trees infected by the D pathotype developed from late fall to early winter and consisted of early drop of green, infected leaves that eventually gave rise to complete defoliation and necrosis of branches (Fig. 1B). Conversely, two characteristic syndromes, designated apoplexy (or acute form of the disease) and slow decline (or chronic form), developed in trees infected by the ND pathotype. Apoplexy developed mainly by late winter and was characterized by a quick dieback of olive twigs and branches where leaves turned light-brown, rolled back toward the abaxial side, dried up and remained attached to the symptomatic shoots (Fig. 1C). Slow decline occurred in springtime, by the time of flowering, and consisted mainly of flower mummification and necrosis of inflorescences, together with necrosis of leaves on symptomatic shoots that fell off except for leaves located at the distal end of shoots. 
The highest number of newly diseased trees (39\%) appeared during the first cropping season (1999/2000) following the first detection of Verticillium wilt in the orchard. Most of infections by ND V. dahliae occurred during this first season, with only 4 out of the total 18 ND V. dahliae-infected trees becoming symptomatic during the time period of 2001/2002. Conversely, symptomatic trees infected by D $V$. dahliae continued to appear during the four cropping seasons of the experiment (Fig. 2A). The increase in disease incidence over time across the 1999 to 2003 period was adequately described by the generalized logistic model of multiple sigmoid pattern both for infections by $\mathrm{D}$ or ND $V$. dahliae as well as for the total number of infections $\left(R^{2}>0.98\right)$ (Fig. 2). Overall, the apparent infection rate in the fitted model was highest in the late winter to early spring period, decreased with time to minimum values in the summer to fall period, and increased again thereafter (Fig. 2B). The maximum apparent infection rate by the ND pathotype was slightly delayed with respect to that by the $\mathrm{D}$ pathotype. This temporal pattern of disease increase was indicated by distinct waves across the four cropping seasons in the derivative function of the disease incidence progress curves for the total number of infections as well as for infections by $\mathrm{D} V$. dahliae (Fig. 2B). However, the curve of increase of infections by ND $V$. dahliae presented only two waves in the derivative function (cropping seasons 1999 to 2000, and 2001 to 2002), with no further growth phases in the second and fourth cropping seasons (Fig. 2B). The estimates for the upper asymptote (parameters $p_{11}$ to $p_{14}$ in the logistic equation) for each of the four cropping seasons were respectively: $3.28,0.82,1.66$, and 2.01 for the total number of infected trees; $2.45,0.82,1.62$, and 1.89 for those infected by the D pathotype; and $0.78,0.00,0.22$, and 0.00 for those infected by the ND pathotype. Similarly, the estimates for the rate of disease incidence increase (parameters $p_{31}$ to $p_{34}$ in the logistic equation) for each of the four cropping seasons were respectively: $0.029,0.032,0.019$, and 0.017 for the total number of infected trees; $0.026,0.032,0.019$, and 0.017 , for those infected by the D pathotype; and $0.035,0.000,0.026$, and 0.000 for those infected by the ND pathotype.

Genetic variability of $\boldsymbol{V}$. dahliae isolates. Results from cluster analysis of MP-PCR fingerprintings grouped $V$. dahliae isolates from olive trees into three distinctive groups (Fig. 3). The D isolates were divided in two main groups (Groups I and II) and comprised five main clusters based on a similarity score of $59.4 \%$. Most D isolates analyzed (89\%) were in Group II and belonged to a single genotype (i.e., shared the same fingerprinting profile; similarity score $96.5 \%$ ) though they were obtained from trees located across the orchard (Fig. 3). This fingerprinting was identical to that obtained for soil $V$. dahliae isolates sampled from the plot frequently cropped to cotton (isolates V-985, V-987, and V-988) (Fig. 3) that were characterized as members of the D pathotype by the specific-PCR assay (data not shown). Group I contained the reference isolate V-138I of the D pathotype and five tree isolates of the $\mathrm{D}$ pathotype that were of different genotype (Fig. 3). Interestingly, these isolates originated from trees that were among those that first showed severe wilt and defoliation in the first years (1999 and 2000) of the study. Group III included all olive isolates of the ND pathotype and the reference isolate V176I of the ND pathotype that differed much in their fingerprintings among themselves and with $\mathrm{D}$ pathotype isolates.

Spatial pattern analyses. Ordinary runs. Ordinary runs analysis indicated aggregation of Verticillium wilt-diseased trees in 84.8 and $66.7 \%$ of the 33 assessment dates for within- and across-rows, respectively (data not shown). Across-row aggregation of diseased trees was not detected until mid May of 2000, 6 months after appearance of symptoms. Later on, aggregation of diseased trees increased from 2.8 to $8.3 \%$ of rows by the end of the experiment (Table 1). Across-row aggregation of diseased trees increased from 2.1 to $6.3 \%$ from December 1999 to November 2001 , but decreased thereafter to $4.2 \%$ of rows by May
2002, and was nil during the last cropping season, 2002 to 2003. Except for that later period for which no within-row aggregation was identified, the proportion of aggregation of Verticillium wiltdiseased trees within rows often exceeded that across rows (Table 1).

The next level of aggregation examined was the association of disease status within quadrats of various sizes.

Binomial index of dispersion. The values of the $I_{\beta}$ index of dispersion suggested significant spatial aggregation of Verticillium wilt-diseased trees for different quadrat sizes over time (Table 1). When significant heterogeneity occurred, it generally included quadrat sizes from $2 \times 2$ to $4 \times 4$ trees; however, the intensity of that heterogeneity varied among assessment dates. In particular, most of the significant values of $I_{\beta}$ were found for disease assessments made from May 2001 till the end of the experiment in May 2003. The $I_{\beta}$ index of dispersion generally increased over time as well as with the increase in disease incidence and quadrat size (Table 1, Fig. 4). An exception to this trend occurred for quadrat size $2 \times 2$ for which $I_{\beta}$ tended to decrease from 2001 (Table 1).

Intraclass correlation. Results of analysis of intraclass correlation index $(k)$ were in agreement with those using the $I_{\beta}$ index of dispersion in indicating an aggregated spatial structure of Verticillium wilt-diseased olive trees for most of the disease
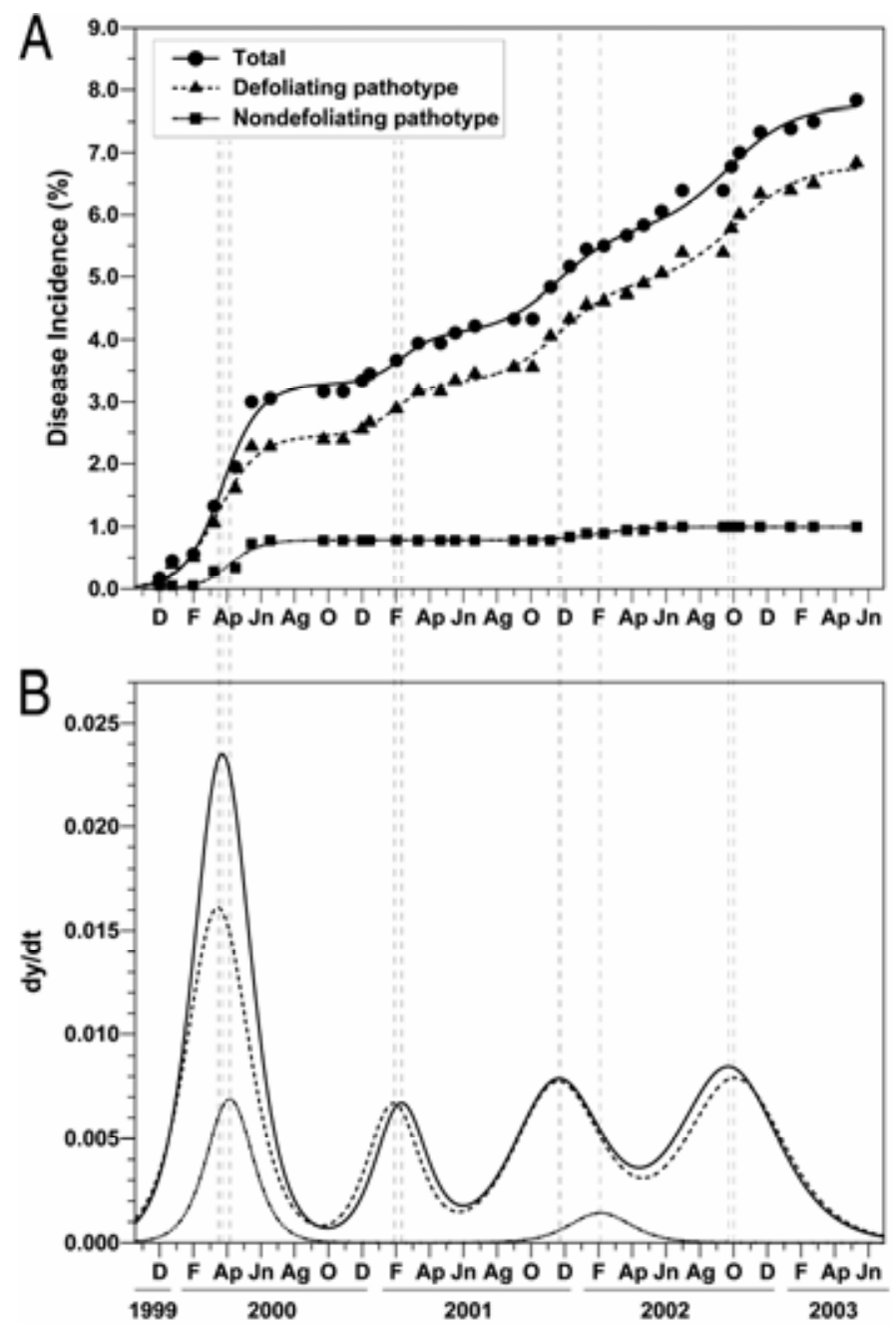

Fig. 2. Temporal progress of Verticillium wilt of olive during four consecutive cropping seasons in southern Spain fitted with a multiple generalized logistic model. A, Observed (symbols) and predicted (lines) disease progress curves for the total disease incidence and for incidence of trees infected by either the defoliating or the nondefoliating pathotypes of Verticillium dahliae. B, Derivatives of the cumulative disease progress curves. 
assessment dates and quadrat sizes tested (Table 1). Also, results of the intraclass correlation index showed a positive relationship between aggregation of diseased trees and disease incidence except for disease assessments made during the fourth cropping season, 2002 to 2003 (Table 1, Fig. 4). Values of $k$ became smaller as quadrat size increased; indicating less interclass correlation at higher quadrat sizes (Table 1, Fig. 4).

Binary power law. The binary form of Taylor's power law using data from all disease assessment dates gave a good description of the relationship between the observed and binomial variance, $\left(R^{2}=0.99\right.$ to 0.97 ) (Fig. 4). Estimated slopes and intercepts generally increased with quadrat size and were significantly $(P<0.001)$ greater than 1 for all quadrat sizes, indicating a moderate but significant pattern of aggregation of symptomatic trees which varied as a function of disease incidence (Fig. 4).

Relationship between quadrat size and intraclass correlation index and SADIE index of aggregation. Figure 5 shows $k$ for each quadrat size over all levels of disease incidence. Positive $k$ values decreased approximately linearly with the natural logarithm of quadrat size for most cases (Fig. 5A). Coefficient of variation of estimates of $k$ across quadrat size for each level of disease incidence ranged 5.8 to 244.7 (mean value $64.63 \pm 7.68$ ). In contrast, the estimates of the SADIE index of aggregation $\left(I_{a}\right)$ for each level of disease incidence were relatively invariant, to variation in the quadrat size used, especially for quadrat sizes 2 $(2 \times 1)$ and $4(2 \times 2)$ (Fig. 5B). The coefficient of variation of estimates of $I_{a}$ across quadrat size for each level of disease incidence ranged 0.6 to 6.5 (mean value $3.21 \pm 0.28$ ) (Fig. 5B). Consequently, quadrat size $2 \times 2$ was selected for further analyses.

Spatial pattern of Verticillium wilt diseased trees. The spatial pattern of Verticillium wilt-diseased olive trees in the orchard over time is illustrated in Figure 6. Diseased trees were initially scattered without discernible pattern over the entire orchard, but from late-winter 2000 to the end of the experiment, newly diseased trees appeared more frequently adjacent to those diseased previously, thereby forming distinct foci of disease patches throughout the field. Most of diseased trees were located in two bands at the south-eastern and central-western side of the orchard (Fig. 6).

Spatial arrangement of quadrats with infected trees. SADIE analysis successfully calculated the distance to regularity $\left(D_{\mathrm{r}}\right)$ and the distribution of distances to regularity under randomizations for all data sets; however this analysis detected nonrandomness less frequently than point pattern analyses (Tables 1 and 2). Overall, significant aggregation was detected using the pooled disease incidence data in 2003 only. Nonetheless, when data were analyzed separately according to the infecting $V$. dahliae pathotype, olive trees infected by the D pathotype showed a significant aggregation in 2003 only, whereas those infected by the ND pathotype were nonaggregated; results for the ND pathotype may have been influenced by its low overall incidence (Table 2, Fig. 6).

The index of aggregation $\left(I_{a}\right)$ calculated with the incidence of total infections (total disease incidence) and the incidence of infections by the D pathotype indicated that aggregation of quadrats with diseased trees was significant only for the disease assessment made from December 2002 until the end of the experiment in May 2003 (data not shown). Computation of the indices of clustering for patch $\left(v_{i}\right)$ and gaps $\left(v_{j}\right)$ was congruent with these results. Overall, $I_{a}$ and $v_{i}$ values increased with time and consequently $P_{a}$ values decreased, indicating an intensification of clustering from one cropping season to the next. Thus, SADIE analysis suggested a random pattern of distribution of Verticillium wilt-diseased olives until October 2002, but a significant aggregated pattern $\left(I_{a}=1.41\right.$ to $\left.1.75 ; P_{a}<0.05\right)$ for disease assessments

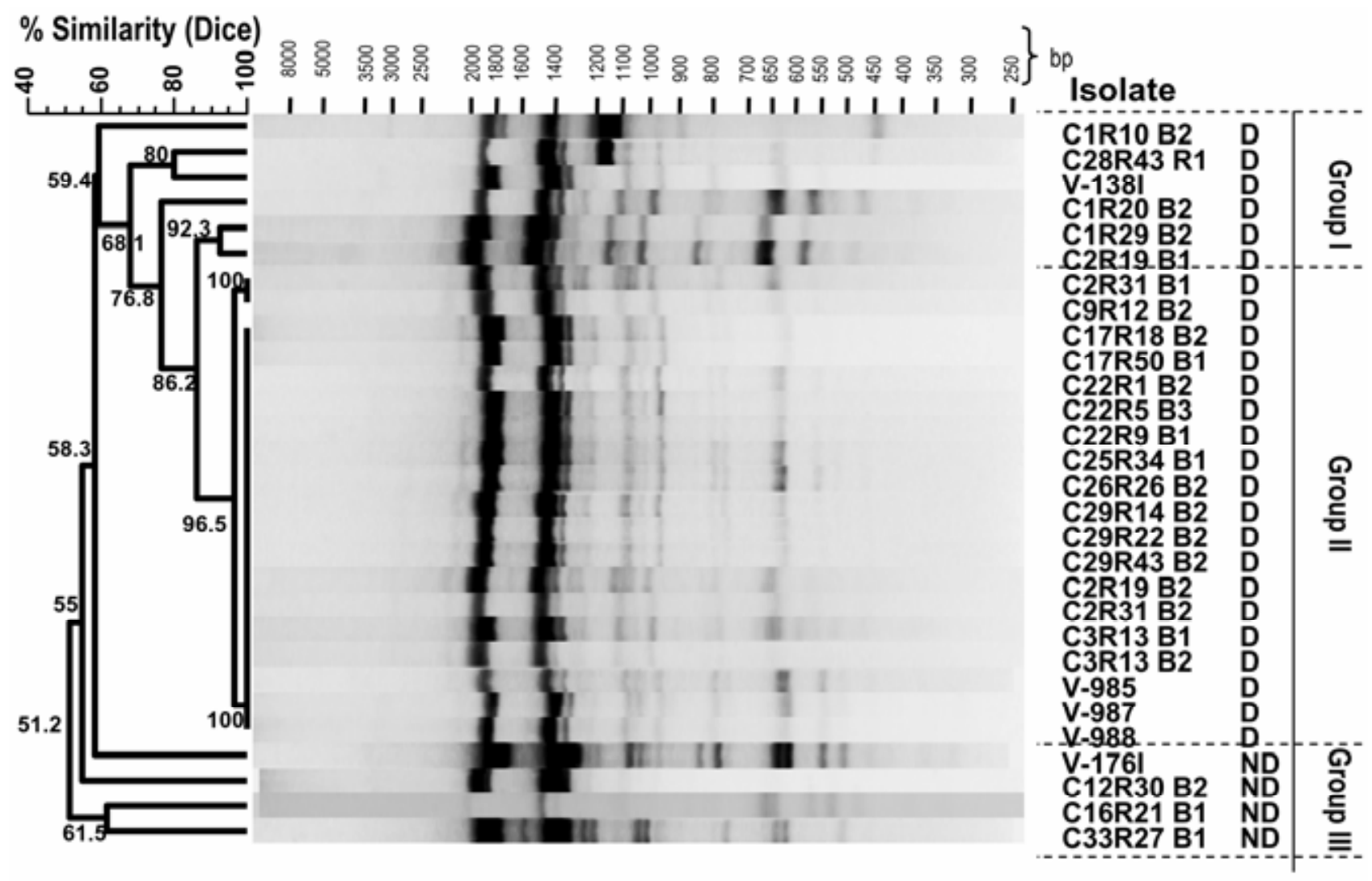

Fig. 3. Cluster analysis of genomic fingerprinting patterns generated by microstelite polymerase chain reaction (MP-PCR) analysis using the M13 repetitive core sequence primer of representative defoliating (D) and nondefoliating (ND) Verticillium dahliae isolates. Each isolate is labeled by the location of the diseased olive tree from which isolated (C, column; R, row, and B, branch of the tree). V. dahliae isolates V-985, V-987, and V-988 were obtained from soil sampled from a field plot nearby the 'Arbequina' orchard. Isolates V-176I and V-138I were used as representative of the ND and D pathotypes of V. dahliae, respectively. 
made from December 2002 through the end of the fourth experimental cropping season in May 2003 (Table 2, Fig. 7). The intensification of clustering was also indicated by a general increase in size of the main patch clusters. Often, there was a large patch cluster and one to several smaller ones. The size of the main patch cluster remained constant during the first two cropping seasons ( 1 quadrat, 4 trees, $49 \mathrm{~m}^{2}$ ), but from July 2002 to May 2003 that size increased from 3 to 11 quadrats (44 trees, $539 \mathrm{~m}^{2}$ ) when trees infected by D or ND V. dahliae were analyzed jointly, and from 3 to 12 quadrats ( 48 trees, $588 \mathrm{~m}^{2}$ ) when only the D-infected trees were considered (Table 2).

Patch clusters often extended in the direction across rows, and in some cases shared a boundary with one edge of the plot, in particular with the south-eastern edge. The second order patch clusters (i.e., biggest sized path cluster excluding main cluster) were generally much smaller, extending the total disease incidence from 1 quadrat in spring of 2001 to 2 and 7 quadrats in that of 2002 and 2003, respectively. Interestingly, the size of second order patch clusters of D $V$. dahliae-infected trees at the end of the experiment was 10 quadrats, (i.e., 3 quadrats higher than that observed for the incidence of total infections) (Table 2). Centroids of the second order patch cluster were located up to 40 $\mathrm{m}$ from the main clusters, with slight differences between the total incidence of infections and the incidence of infections by $\mathrm{D} V$. dahliae only, preferentially along rows; however, centroids of smaller order patch clusters could be located as far as $196 \mathrm{~m}$ from the main cluster centroid. The strongest clustering was detected for the disease assessments made from December 2002 to the end of May 2003 (Fig. 8). Such clustering was essentially related to a strong contrast between very large patches of infections defined by main and second order clusters located mainly at the eastern side of the orchard and large, sparse areas with diseased trees located on the central-western side and no or few small clusters in the rest of the orchard (Fig. 7).

Similarly to the increase in $I_{\mathrm{a}}$, during the first two cropping seasons, 1999 to 2000 and 2000 to 2001, the number of patch clusters defined by the total number of infections or only by $\mathrm{D} V$. dahliae-infected trees increased only from 1 to 4 patch clusters that covered 0.2 to $1.2 \%$ of the plot (data not shown). Conversely, during the last two cropping seasons, 2001 to 2002 and 2002 to 2003 , the number of, and area covered by patch clusters including total infections, increased more rapidly to reach 10 patch clusters and $2.8 \%$ of the orchard area by spring 2002 , and 33 path clusters and $13.9 \%\left(2,940 \mathrm{~m}^{2}\right)$ of that area by May 2003 . However, when only the trees infected by ND $V$. dahliae were considered the number of, and area covered by, patch clusters was nil or accounted for only two clusters covering $0.5 \%$ of the area during the last two crop seasons (Table 2, Fig. 8). On the other hand, the number of patch clusters including olive trees infected by the $\mathrm{D} V$. dahliae increased from 2 in the spring of 2001 to 6 in 2002 and 29 in 2003. During those same time periods, the area covered by patch clusters with trees infected by D. V. dahliae was $0.7,2.1$, and $13.7 \%$ of the orchard area, respectively (Table 2, Fig. 8).

Spatiotemporal analysis. Strong significant spatial associations $(P<0.05)$ were found when maps of spatial aggregation of Verticillium wilt-diseased trees were compared among successive

TABLE 1. Disease incidence, ordinary runs, binomial dispersion index $(D)$, and interclass correlation $(k)$ analyses for Verticillium wilt of olive in southern Spain

\begin{tabular}{|c|c|c|c|c|c|c|c|c|c|c|c|}
\hline \multirow[b]{2}{*}{$\begin{array}{l}\text { Date of } \\
\text { assessment }^{\mathrm{a}}\end{array}$} & \multirow[b]{2}{*}{$\begin{array}{c}\text { Disease } \\
\text { incidence }(\%)\end{array}$} & \multicolumn{2}{|c|}{ Ordinary runs ${ }^{\mathrm{b}}$} & \multicolumn{4}{|c|}{ Dispersion index $(D)^{\mathrm{c}}$} & \multicolumn{4}{|c|}{ Interclass correlation $(k)^{\mathrm{d}}$} \\
\hline & & $\begin{array}{l}\text { Within } \\
\text { row }\end{array}$ & $\begin{array}{c}\text { Across } \\
\text { row }\end{array}$ & $\begin{array}{c}\text { Quadrat } \\
\text { size } 1 \times 2\end{array}$ & $\begin{array}{c}\text { Quadrat } \\
\text { size } 2 \times 2\end{array}$ & $\begin{array}{c}\text { Quadrat } \\
\text { size } 2 \times 4\end{array}$ & $\begin{array}{c}\text { Quadrat } \\
\text { size } 4 \times 4\end{array}$ & $\begin{array}{c}\text { Quadrat } \\
\text { size } 1 \times 2\end{array}$ & $\begin{array}{c}\text { Quadrat } \\
\text { size } 2 \times 2\end{array}$ & $\begin{array}{c}\text { Quadrat } \\
\text { size } 2 \times 4\end{array}$ & $\begin{array}{c}\text { Quadrat } \\
\text { size } 4 \times 4\end{array}$ \\
\hline $11 / 24 / 99$ & 0.167 & 0 & 0 & 1.00 & 1.00 & 0.99 & 0.98 & -0.001 & -0.001 & -0.001 & -0.001 \\
\hline $12 / 17 / 99$ & 0.444 & 0 & 0.021 & 1.00 & 0.99 & 0.97 & 0.94 & -0.004 & -0.004 & -0.004 & -0.004 \\
\hline $01 / 25 / 00$ & 0.556 & 0 & 0.021 & 1.00 & 0.99 & 0.97 & 0.93 & -0.004 & -0.005 & -0.005 & -0.005 \\
\hline 03/03/00 & 1.333 & 0 & 0.021 & 0.99 & 1.05 & 1.09 & 1.16 & -0.012 & 0.017 & 0.012 & 0.011 \\
\hline $04 / 11 / 00$ & 1.944 & 0 & 0.042 & 0.98 & 1.01 & 0.99 & 1.03 & -0.018 & 0.002 & -0.001 & 0.002 \\
\hline $05 / 11 / 00$ & 3.000 & 0.028 & 0.063 & 1.01 & 1.03 & 1.03 & 1.02 & 0.010 & 0.009 & 0.004 & 0.001 \\
\hline $06 / 14 / 00$ & 3.056 & 0.028 & 0.063 & 1.01 & 1.02 & 1.02 & 1.00 & 0.008 & 0.008 & 0.002 & 0.001 \\
\hline $09 / 20 / 00$ & 3.167 & 0.028 & 0.063 & 1.01 & 1.02 & 1.04 & 1.00 & 0.006 & 0.005 & 0.005 & 0.001 \\
\hline $11 / 30 / 00$ & 3.333 & 0.028 & 0.063 & 1.00 & 1.05 & 1.06 & 1.04 & 0.003 & 0.015 & 0.008 & 0.003 \\
\hline $12 / 14 / 00$ & 3.444 & 0.028 & 0.063 & 1.00 & 1.04 & 1.07 & 1.08 & 0.001 & 0.012 & 0.010 & 0.005 \\
\hline $02 / 01 / 01$ & 3.667 & 0.056 & 0.063 & 1.03 & 1.05 & 1.10 & 1.10 & 0.029 & 0.018 & 0.015 & 0.007 \\
\hline 03/13/01 & 3.944 & 0.056 & 0.063 & 1.05 & 1.09 & $1.18^{*}$ & 1.19 & 0.052 & 0.031 & 0.025 & 0.013 \\
\hline $05 / 21 / 01$ & 4.111 & 0.056 & 0.063 & 1.05 & $1.14^{*}$ & $1.21^{*}$ & $1.25^{*}$ & 0.046 & 0.046 & 0.029 & 0.017 \\
\hline $06 / 26 / 01$ & 4.222 & 0.028 & 0.063 & 1.04 & $1.13^{*}$ & $1.21^{*}$ & $1.24^{*}$ & 0.043 & 0.043 & 0.030 & 0.016 \\
\hline $10 / 08 / 01$ & 4.333 & 0.028 & 0.063 & $1.07^{*}$ & $1.15^{*}$ & $1.23^{*}$ & $1.33^{*}$ & 0.069 & 0.050 & 0.033 & 0.022 \\
\hline $11 / 12 / 01$ & 4.833 & 0.028 & 0.063 & 1.05 & $1.13^{*}$ & $1.23^{*}$ & $1.29^{*}$ & 0.052 & 0.043 & 0.034 & 0.020 \\
\hline $12 / 17 / 01$ & 5.167 & 0.028 & 0.042 & 1.04 & $1.10^{*}$ & $1.17^{*}$ & $1.24^{*}$ & 0.042 & 0.033 & 0.024 & 0.016 \\
\hline $01 / 17 / 02$ & 5.444 & 0.028 & 0.042 & 1.06 & $1.12^{*}$ & $1.19^{*}$ & $1.25^{*}$ & 0.056 & 0.041 & 0.027 & 0.017 \\
\hline $02 / 18 / 02$ & 5.500 & 0.056 & 0.042 & 1.05 & $1.12^{*}$ & $1.20^{*}$ & $1.25^{*}$ & 0.054 & 0.039 & 0.029 & 0.017 \\
\hline 04/01/02 & 5.667 & 0.083 & 0.042 & 1.05 & $1.10^{*}$ & $1.21^{*}$ & $1.23^{*}$ & 0.049 & 0.034 & 0.030 & 0.016 \\
\hline $05 / 02 / 02$ & 5.833 & 0.083 & 0.042 & $1.07^{*}$ & $1.11^{*}$ & $1.20^{*}$ & 1.22 & 0.065 & 0.037 & 0.029 & 0.014 \\
\hline 06/04/02 & 6.056 & 0.083 & 0 & $1.06^{*}$ & 1.09 & $1.18^{*}$ & 1.18 & 0.058 & 0.031 & 0.026 & 0.012 \\
\hline 07/12/02 & 6.389 & 0.083 & 0 & $1.07^{*}$ & 1.09 & $1.18^{*}$ & 1.16 & 0.067 & 0.028 & 0.026 & 0.010 \\
\hline $10 / 10 / 02$ & 6.778 & 0.056 & 0 & 1.06 & 1.06 & 1.15 & 1.19 & 0.055 & 0.018 & 0.021 & 0.012 \\
\hline $10 / 25 / 02$ & 7.000 & 0.083 & 0 & $1.07^{*}$ & 1.07 & $1.18^{*}$ & 1.21 & 0.066 & 0.025 & 0.026 & 0.014 \\
\hline $12 / 02 / 02$ & 7.333 & 0.083 & 0 & 1.06 & 1.05 & $1.17^{*}$ & $1.26^{*}$ & 0.056 & 0.016 & 0.024 & 0.018 \\
\hline $01 / 27 / 03$ & 7.389 & 0.083 & 0 & 1.05 & 1.05 & $1.16^{*}$ & $1.24^{*}$ & 0.055 & 0.015 & 0.023 & 0.016 \\
\hline 03/10/03 & 7.500 & 0.083 & 0 & 1.05 & 1.05 & $1.17^{*}$ & $1.28^{*}$ & 0.051 & 0.018 & 0.025 & 0.019 \\
\hline $05 / 28 / 03$ & 7.833 & 0.083 & $\mathbf{0}$ & $1.07^{*}$ & 1.06 & $1.18^{*}$ & $1.27^{*}$ & 0.074 & 0.020 & 0.026 & 0.018 \\
\hline
\end{tabular}

a Bold data indicate disease assessment made at the end of each crop season.

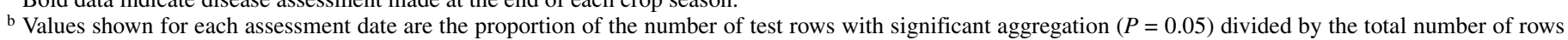
tested.

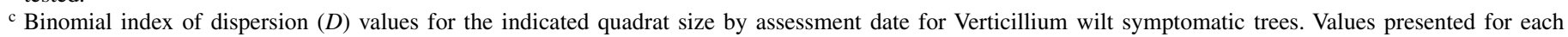
assessment date are $D$ (=observed variance/binomial variance). Significances (*) were calculated using the C( $\alpha)$ statistic. Values of $D$ not significantly different

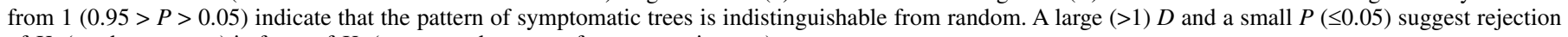
of $H_{0}$ (random pattern) in favor of $H_{1}$ (aggregated pattern of symptomatic trees).

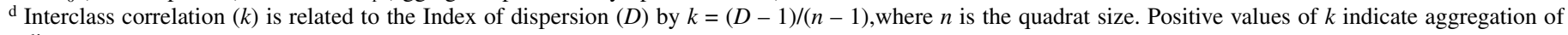
disease. 
time periods irrespective of the $V$. dahliae pathotype infecting a tree (Table 3). This indicates that the new patches of diseased trees appearing over time were mainly a result of coalescence among preexisting ones or were located in their proximity, thus causing no significant $(P \geq 0.05)$ modification of the spatial distribution of the diseased trees even with increasing values of disease incidence and number and size of patch clusters (Fig. 7).
Spatial association between spatial patterns of distribution of olive trees infected by the $D$ and ND $V$. dahliae pathotypes. A nonsignificant $(P \geq 0.05)$ association was found when the spatial pattern of trees infected by the $\mathrm{D}$ pathotype by springtime of each cropping season in the study was compared with that of trees infected by the ND pathotype (Table 3, Fig. 7). Thus, a random distribution was found for trees infected by ND
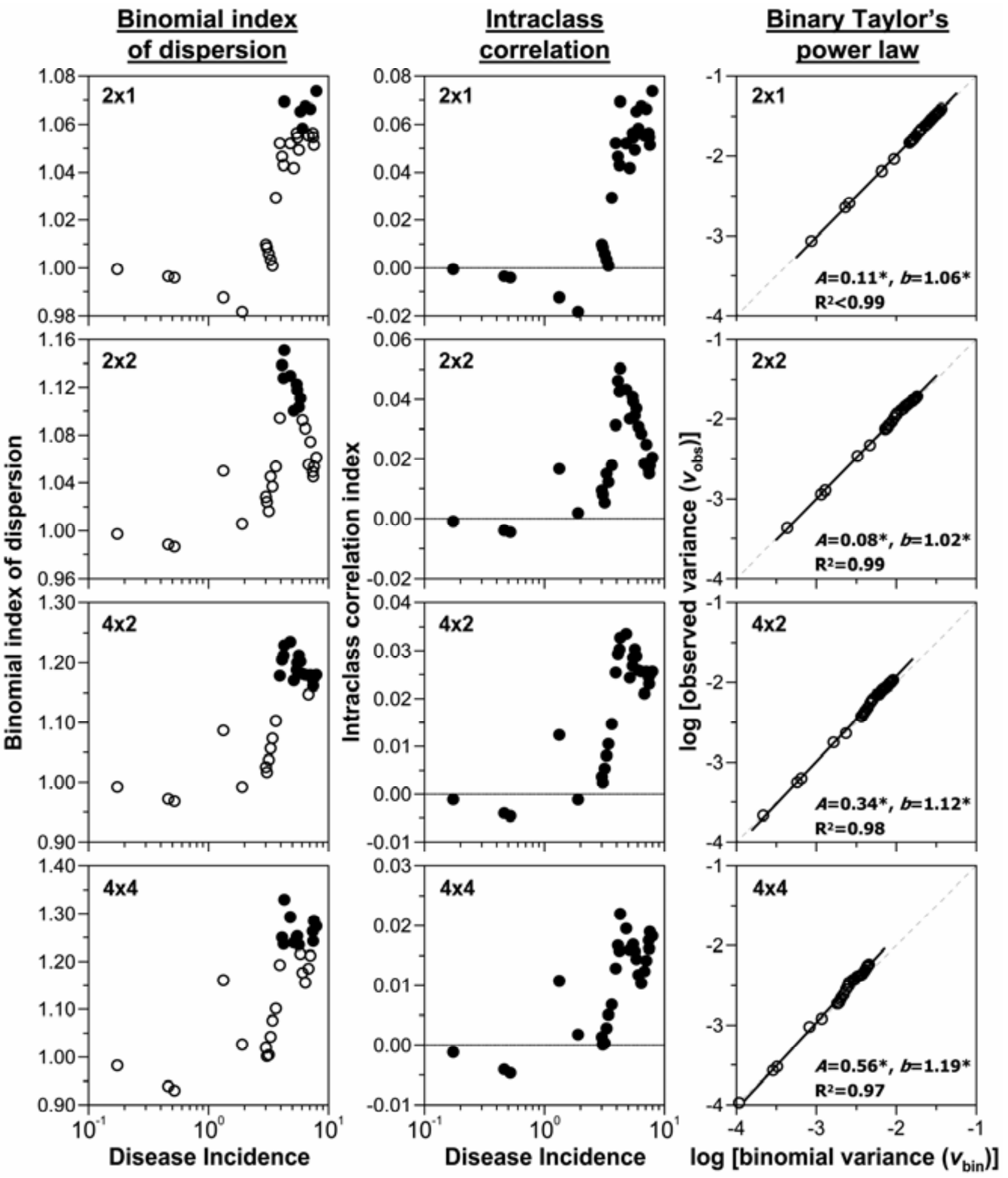

Fig. 4. Binomial index of dispersion, intraclass correlation and Binary Taylor's power law for four quadrat sizes based on disease incidence of Verticillium dahliae-infected olive trees in southern Spain. Each data point represents a disease assessment date. For the binomial index of dispersion, open circles and closed circles represent disease assessments with random and aggregated patterns, of infected olive trees $(P<0.05)$, respectively. For the intraclass correlation index, positive values indicate aggregation of infected olive trees. For the Binary Taylor's power law, the solid lines represents the relationship $\log \left(v_{\mathrm{obs}}\right)=\log (A)+b$ $\log \left(v_{\text {bin }}\right)$ fitted to the data by least squares-regression. A parameter value followed by an asterisk indicates that the parameter is significantly different $(P<0.05)$ from 0 (intercept, $A$ ) or 1 (slope, $b$ ), $R^{2}=$ coefficient of determination. The dashed lines represent the binomial line when observed variance $=$ binomial variance. 
$V$. dahliae, whereas trees infected by $\mathrm{D} V$. dahliae showed an aggregated pattern. Also, the extent of clustering of trees infected by the D pathotype increased gradually over time, whereas no increase occurred in the clustering of trees infected by the ND pathotype (Fig. 7).

\section{DISCUSSION}

In this study, use of temporal and spatial analyses of Verticillium wilt epidemics in olive, together with DNA fingerprinting (MP-PCR) of $V$. dahliae isolates infecting the trees, allowed us to track the spread of genotypes of the pathogen throughout an olive orchard and infer possible sources of inoculum for development of Verticillium wilt epidemics. To our knowledge, this is the first time that temporal and spatial analyses techniques are used to quantify the development of Verticillium wilt epidemics in olive.

To achieve our aims, we used several correlation-based and point pattern analyses for the characterization of the spatial pattern of Verticillium wilt epidemics in an experimental, high tree-density olive orchard at southern Spain over four consecutive cropping seasons. Each of those spatial analyses provided discrete, but complementary, information about the spatial pattern of
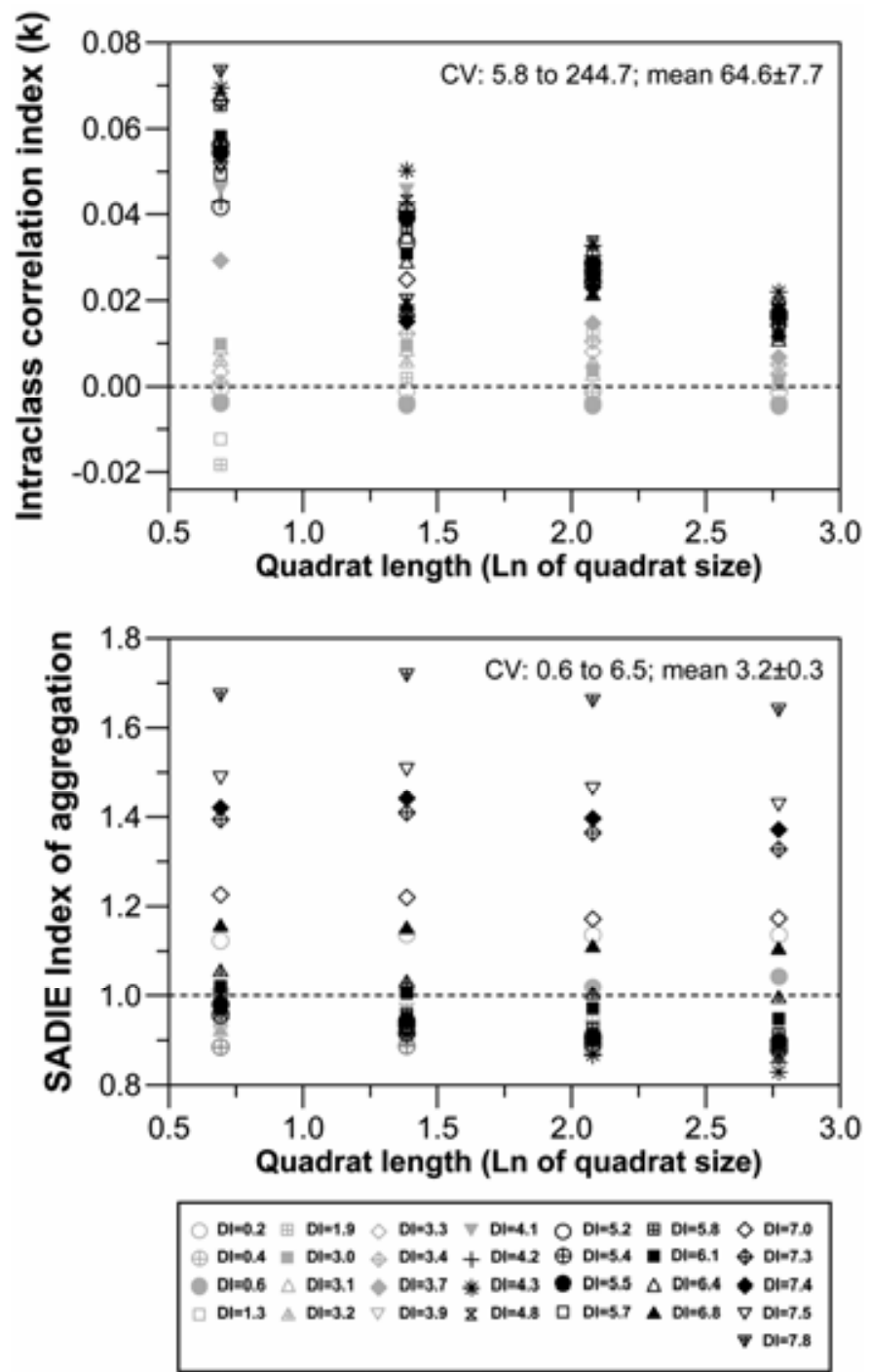

Fig. 5. Relationship between quadrat size and intraclass correlation index $(k)$ (top), and spatial analysis by distance indices (SADIE) index of aggregation $\left(I_{a}\right)$ (bottom), for Verticillium wilt incidence in olive trees in southern Spain. $\mathrm{CV}$, Coefficient of variation across quadrat size for each disease incidence level (range and mean \pm standard error). distribution of Verticillium wilt-diseased olive trees in the orchard, and consequently provided a global view of the disease expansion process. This approach, first proposed by Madden and Hughes (31), proved efficient for describing spatial dynamics in several pathosystems characterized by systemic or local infections $(1,9,16,38,44)$.

In our study, descriptions of Verticillium wilt epidemics in olive trees were based on a seemingly simple annual infection cycle that gave rise to sigmoid-shaped curves of disease incidence increase over an annual cropping season, and polyetic epidemics over the sequence of four cropping seasons in the study (Fig. 2).
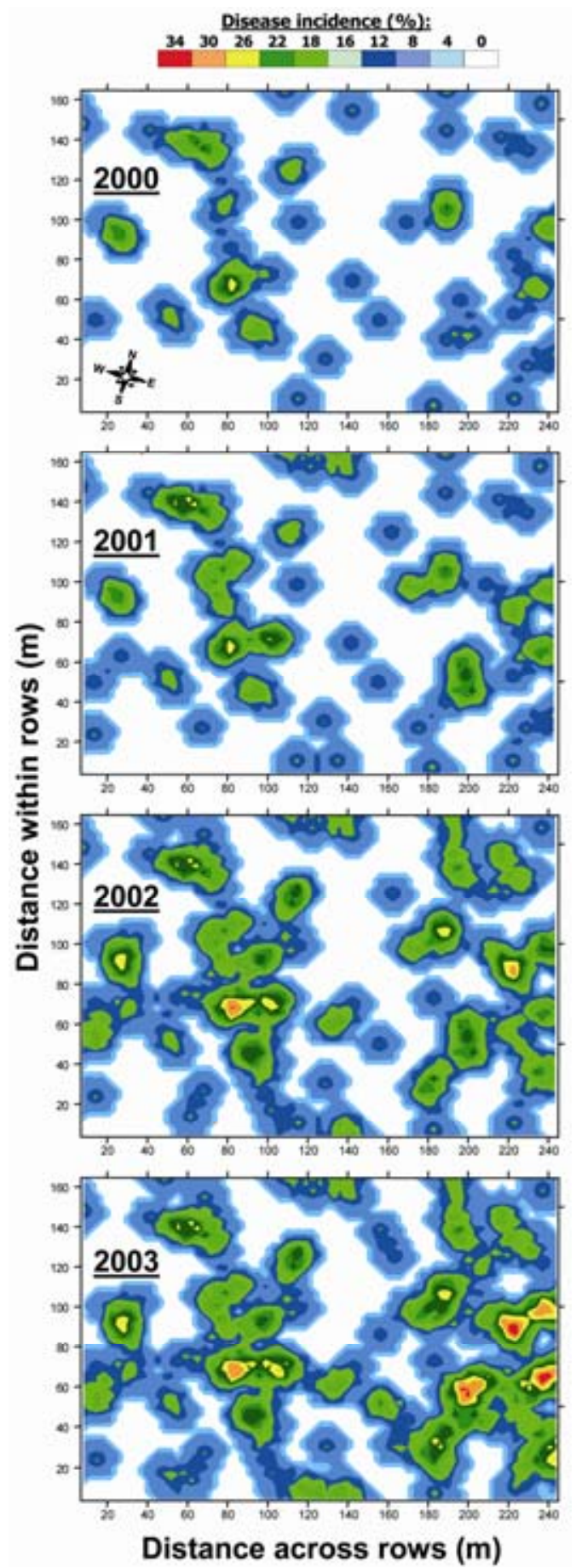

Fig. 6. Kriging estimate maps based on Verticillium wilt incidence in olive trees in southern Spain in the spring of each of 2000, 2001, 2002, and 2003 crop seasons. Axes show distances in meters of olive trees with $y$ axis in the direction of rows of trees. The darker the shading the higher the disease incidence. 
The biological and ecological characteristics of pathogen life cycles and diseases are the primary determinants of the spatial pattern of epidemics (7). In this present study, spatial pattern analyses were used and interpreted to generate hypotheses about the putative origin of primary inoculum for epidemics and further, about within-field dispersal of pathogen propagules and spatial pattern of diseased plants.

For the majority of disease assessment dates, a degree of aggregation was detected among diseased trees by ordinary runs analysis (Table 1). These findings indicate that the status of a diseased tree influences the status of immediately adjacent trees, such an influence being stronger within rows compared with that between them. The next level of spatial scale examined was the association of diseased trees within quadrats of various sizes. Interpretation of both the beta-binomial index of dispersion $D$ and the intraclass correlation $k$ values suggests a significant nonrandom spatial structure (i.e., aggregation) of diseased trees that occurred for most disease assessments and quadrat sizes over time as disease incidence became higher than 0.04 (occurring in June 2000), almost 2 years after symptoms were observed in the first diseased trees (Table 1, Fig. 3). In general, when aggregation was indicated at more than one quadrat size the significant $D$ values increased and $k$ values decreased as quadrat sizes became larger (Fig. 5A). This is in agreement with previous reports (13) which demonstrate the explicit dependence of these two variables. Conversely, there was no significant change in the estimates of the SADIE index of aggregation with quadrat size (Fig. 5B). Estimated parameters of the binary form of Taylor's power law indicated an overall aggregation of Verticillium wilt-infected trees, with $b>1$ for all quadrat sizes examined, suggesting that aggregation at individual assessment dates was predicted to depend on disease incidence (22).

Primary inoculum for Verticillium wilt of olive can be either soilborne microsclerotia or $V$. dahliae structures in infected seeds or planting material $(35,47)$. In our study, the distribution of Verticillium wilt-diseased olive trees in the orchard followed aggregated patterns, similarly to that described for diseases caused by other soilborne pathogens (7). An aggregated pattern of diseased plants may correspond to an aggregated distribution of the pathogen in the primary source of inoculum, but also results from secondary infections by the spread of inoculum from primary foci to healthy plants (15). For $V$. dahliae, as a typical monocyclic pathogen at one season scale (15), the spatial distribution of soilborne microsclerotia $(3,5,24,52)$ as well as their amount $(4,18,34)$ at planting play a critical role in the spatial patterns of diseased plants and wilt development in many crops.

Potential means for $V$. dahliae dispersal within and across olive orchards include the dispersal of pathogen propagules in soil by furrow and flood irrigation or machinery, as well as dispersal of leaves and refuse from $V$. dahliae-infected olive and cotton crops $(10,23,41,47,48-50)$. In our study, we hypothesize that the source of inoculum for infections by the ND $V$. dahliae within the olive orchard could be either infected planting material or resident inoculum existing in soil prior to planting. This was based on the observation that a very low (1\%) incidence occurred of olive trees infected by the ND pathotype, with the infected trees being distributed singly along the orchard except for two trees (Table 2, Figs. 7 and 8), and neither increase of disease incidence nor patchiness were detected over time (Fig. 7). Moreover, the number of trees infected by the ND pathotype represented only $12.8 \%$ of the total $V$. dahliae-infected trees, and attacks by ND $V$. dahliae were observed almost exclusively during the first of four cropping seasons in the study. Thereafter, only four new olive trees became infected by ND $V$. dahliae. The nonaggregated spatial distribution of the ND V. dahliae-infected trees, low disease incidence, and 28 months time span from planting to first symptom expression in November 1999, suggest that inoculum of the ND pathotype may have been introduced into the field with nonsymptomatic, infected planting material. That three different genotypes were identified among ND $V$. dahliae isolates assayed by MP-PCR, together with lack of increase in patch size for trees infected by this pathotype, support further this interpretation.

It is possible that the observed epidemic arose from $V$. dahliae inoculum present in the orchard before tree establishment. However, resident ND inoculum in the orchard soil prior to planting would have been likely to be at extremely low inoculum density because of the long history of the orchard being free from $V$. dahliae hosts. Given this, the role of such ND inoculum in initiating disease and sustaining its increase is doubtful. This latter interpretation is supported by results of López-Escudero and Blanco-López (27) who observed no disease after 32 months that 1-year-old extremely susceptible 'Picual' olive plants were transplanted in microplots artificially infested with 10 propagules per gram of soil of ND V. dahliae. In contrast, Levin et al. (26) found

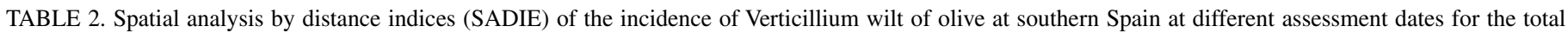
disease incidence as well as for two Verticillium dahliae pathothypes

\begin{tabular}{|c|c|c|c|c|c|c|c|c|c|c|}
\hline \multirow[b]{2}{*}{ Date of assessment $^{\mathrm{a}}$} & \multicolumn{2}{|c|}{ Index of aggregation $^{b}$} & \multicolumn{4}{|c|}{ Index of clustering ${ }^{c}$} & \multicolumn{2}{|c|}{ Patch $^{\mathrm{d}}$} & \multicolumn{2}{|c|}{ Gap } \\
\hline & $I_{a}$ & $P_{a}$ & $V_{i}$ & $P$ & $V_{j}$ & $P$ & $\mathrm{~N}$ & Area $(\%)$ & $\mathrm{N}$ & Area $(\%)$ \\
\hline \multicolumn{11}{|l|}{ Total } \\
\hline 06/14/00 & 0.913 & 0.6784 & 0.908 & 0.6903 & -0.916 & 0.6621 & 1 & $1(0.2)$ & 13 & 47 (10.9) \\
\hline $06 / 26 / 01$ & 0.911 & 0.6812 & 0.926 & 0.6456 & -0.912 & 0.6856 & 3 & $3(0.7)$ & 14 & $35(8.1)$ \\
\hline $07 / 12 / 02$ & 1.029 & 0.3375 & 1.045 & 0.2963 & -1.033 & 0.3219 & 8 & $12(2.8)$ & 17 & $54(12.5)$ \\
\hline $05 / 28 / 03$ & 1.721 & 0.0015 & 1.679 & 0.0015 & -1.707 & 0.0012 & 33 & $60(13.9)$ & 19 & $155(35.9)$ \\
\hline \multicolumn{11}{|c|}{ Nondefoliating pathotype } \\
\hline $06 / 14 / 00$ & 1.040 & 0.3320 & 1.021 & 0.3858 & -1.035 & 0.3499 & 0 & $0(0.0)$ & 12 & $92(21.3)$ \\
\hline $06 / 26 / 01$ & 1.040 & 0.3320 & 1.021 & 0.3858 & -1.035 & 0.3499 & 0 & $0(0.0)$ & 12 & $92(21.3)$ \\
\hline $07 / 12 / 02$ & 1.093 & 0.2413 & 1.073 & 0.2561 & -1.096 & 0.2129 & 2 & $2(0.5)$ & 12 & $98(22.7)$ \\
\hline $05 / 28 / 03$ & 1.093 & 0.2413 & 1.073 & 0.2561 & -1.096 & 0.2129 & 2 & $2(0.5)$ & 12 & $98(22.7)$ \\
\hline \multicolumn{11}{|l|}{ Defoliating pathotype } \\
\hline $06 / 14 / 00$ & 0.932 & 0.5958 & 0.952 & 0.5654 & -0.931 & 0.6243 & 0 & $0(0.0)$ & 14 & $61(14.1)$ \\
\hline $06 / 26 / 01$ & 0.914 & 0.6755 & 0.932 & 0.6117 & -0.915 & 0.6630 & 2 & $3(0.7)$ & 13 & $38(8.8)$ \\
\hline $07 / 12 / 02$ & 1.025 & 0.3556 & 1.064 & 0.2685 & -1.026 & 0.3397 & 6 & $9(2.1)$ & 14 & $73(16.9)$ \\
\hline $05 / 28 / 03$ & 1.747 & 0.0010 & 1.794 & 0.0007 & -1.730 & 0.0012 & 29 & $59(13.7)$ & 17 & $156(36.1)$ \\
\hline
\end{tabular}

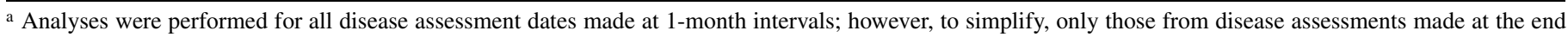
of each crop season are shown.

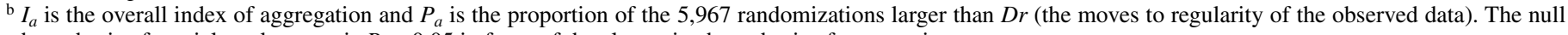
hypothesis of spatial randomness is $P_{a}<0.05$ in favor of the alternative hypothesis of aggregation.

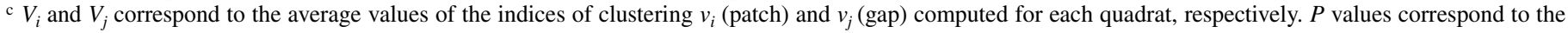
proportion of randomized $V_{i}$ and $V_{j}$ that exceed the observed values.

$\mathrm{d}$ Patchiness and gapiness indicate the number of cluster and are occupied by patch and gap clusters, respectively. 
that $22 \%$ of 'Picual' trees were severely infected by, putatively, ND V. dahliae 18 to 21 moths after planting in a soil that had been cropped to Verticillium wilt-susceptible vegetables for 30 years and thus was presumably highly infested by the pathogen. Therefore, a resident inoculum density of ND $V$. dahliae of significance for initial Verticillium wilt development was not likely to have occurred in the olive orchard of the study, but cannot be completely ruled out, because of the three initially identified infected trees, two were infected by the D pathotype, but one by the ND pathotype.

Other potential means for inoculum dispersal of soilborne $V$. dahliae would include movement of infected plant parts or infested soil particles. These types of dispersal should result in newly infected plants being spread within as well as across rows in an orchard and the appearance of expanding new local or distant clusters of those plants giving rise to a measurable rate of disease incidence increase. In our research, both the multiyear increase in the incidence of trees infected by $\mathrm{D} V$. dahliae together with within-row aggregation of them fit into the characteristics pointed out above. Moreover, we hypothesize that disease increase and aggregation was due to successful infections of new trees by $V$. dahliae inocula provided through dispersal of infected green leaves fallen from trees infected with the D pathotype (41). The higher within-row aggregation of diseased trees could be due to lower distance between adjacent olive trees in a row, $3.5 \mathrm{~m}$, compared to $7 \mathrm{~m}$ distance between adjacent rows.

Our hypothesis is based on the potential of leaves fallen from diseased olive trees as the source of inoculum indicated by (i) the large numbers of $\mathrm{D} V$. dahliae-infected leaves falling from Verticillium wilt-diseased olive trees. An average of 5,580 leaves per month fell from each of 10 infected trees assayed in the orchard during the period of November 2001 through May 2002, of which an average $67.7 \%$ were infected by the pathogen (50); and (ii) the infected leaves proved capable of causing disease to 7month-old 'Arbequina' olives grown in sterile, potted soil artificially infested with chopped leaves and incubated under natural conditions in the orchard (D. Rodríguez-Jurado and R. M. Jiménez-Díaz, unpublished data). A similar relationship with disease was shown for $V$. dahliae-infected maple (Acer platanoides) (20) and European ash (Fraxinus excelsior) (39). For olive trees, inoculum for infections could be either conidia or microsclerotia of the pathogen produced on the fallen, infected leaves $(41,49$, 50). D. Rodríguez-Jurado and R. M. Jiménez-Díaz (unpublished data) found that conidia and mycelia of $V$. dahliae survived for up to 6 weeks when those leaves were placed onto the soil surface underneath olive trees in the orchard, and large numbers of microsclerotia formed in leaves buried for 3 months in moist soil under drip-irrigated trees. Other authors have reported that conidia of $V$. dahliae were capable of surviving up to 2 weeks in soil which may be sufficient time for infection of nearby plants (17). Efficiency for infection of olive roots by inocula derived from the infected, fallen leaves may be enhanced by moist conditions provided by drippers locate close to the trunk as well as by availability of susceptible roots in the proximity of inocula. Fernández et al. (12) found that root density of drip-irrigated 'Manzanillo' olives was higher in the direction along the line of
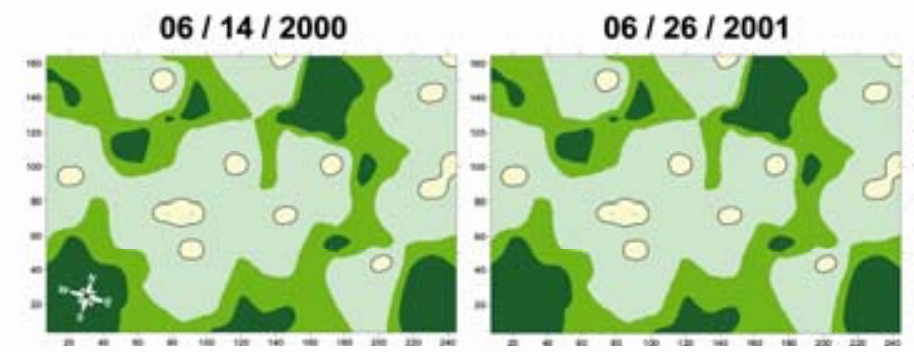

\section{Nondefoliating pathotype incidence}

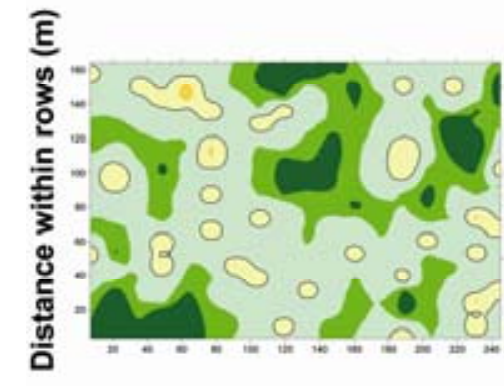

Defoliating pathotype incidence
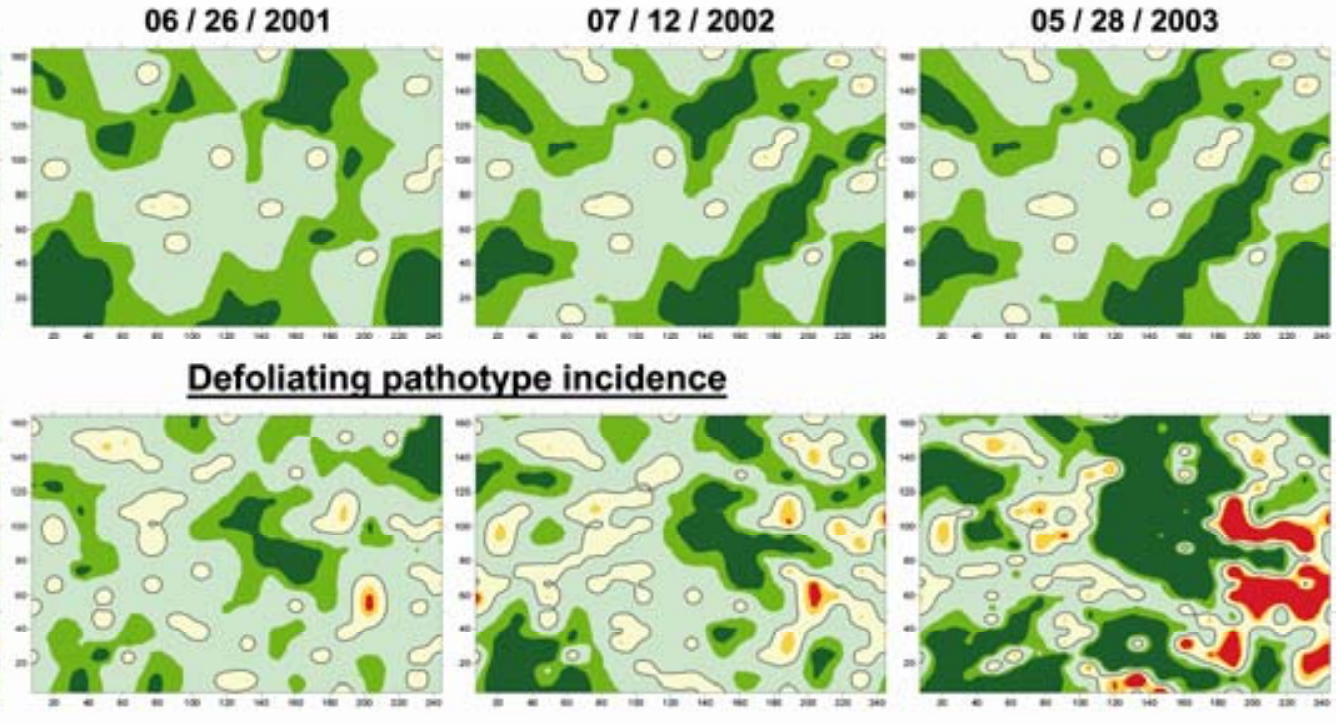

Total disease incidence
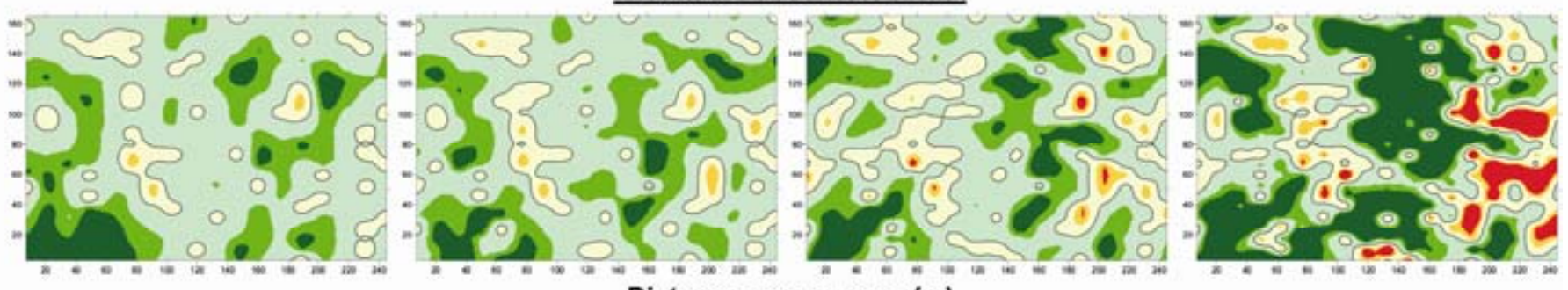

Distance across rows $(\mathrm{m})$

Fig. 7. Map of clustering indices computed with the spatial analysis by distance indices (SADIE) software for the number of Verticillium dahliae-infected trees in the spring of each of 2000, 2001, 2002, and 2003 cropping seasons. Axes show distances in meters of $2 \times 2$ olive trees quadrats with $y$ axis in the direction of rows of trees. Contours enclosing patches with clustering indices $v_{i}>1.5$ (well above expectation) and $1.5>v_{i}>1$ (slightly above expectation) are represented in red and orange, respectively. Similarly, contours enclosing gaps with clustering indices $v_{j}>1.5$ (well above expectation) and $1.5>v_{j}>1$ (slightly above expectation) are represented by dark and light green, respectively. The solid black lines are zero-value contours representing the interpolated boundary between patch and gap regions in light yellow. 

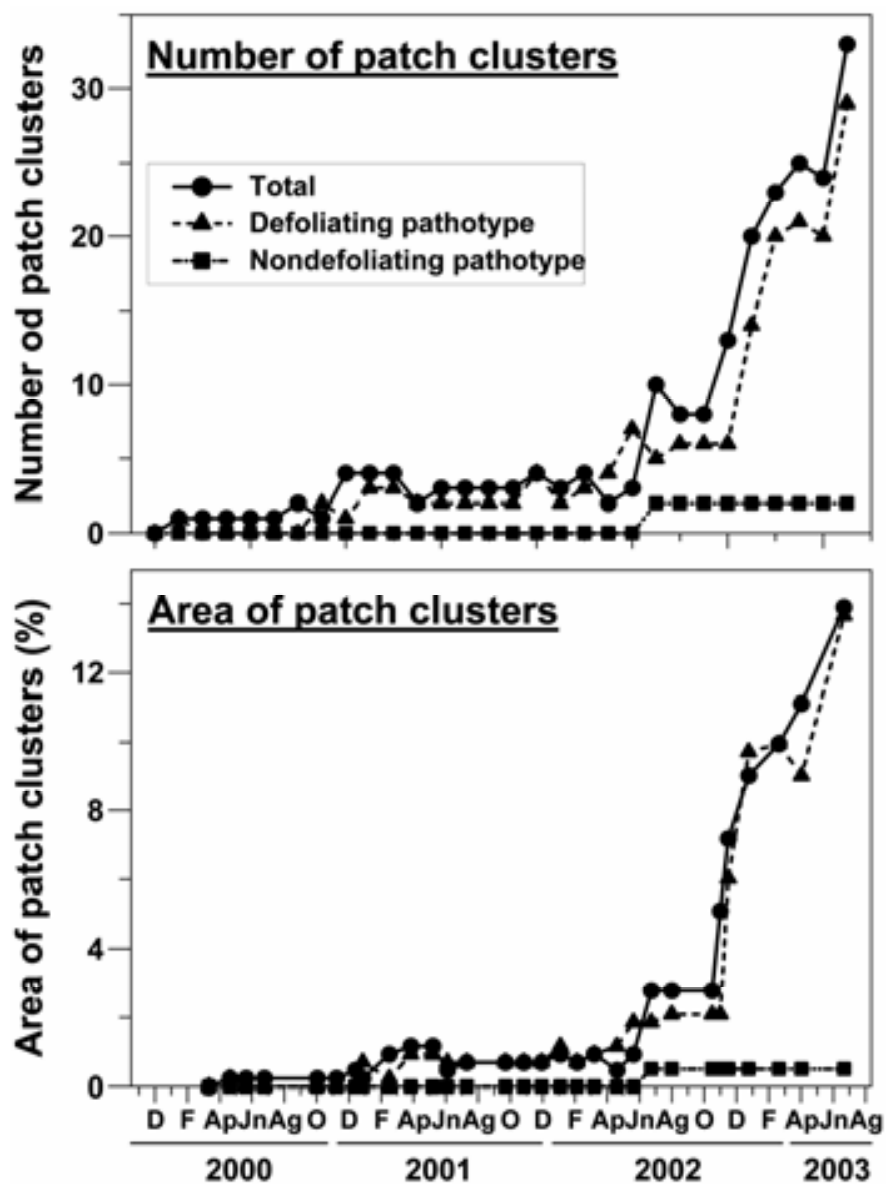

Fig. 8. Temporal progress of number and area covered by path clusters from spatial analysis by distance indices (SADIE) software for Verticillium wilt of olive during four consecutive cropping seasons in southern Spain for the total disease incidence as well as for trees infected by either the defoliating or the nondefoliating pathotypes of Verticillium dahliae. A patch cluster is defined when the clustering index $v_{i}>1.5$. Each data point represents a disease assessment date. drippers (i.e., along row) than in the perpendicular direction (i.e., across rows). A high density of fine roots $(<0.5 \mathrm{~mm}$ in diameter) occurred within $20 \mathrm{~cm}$ soil depth within $1 \mathrm{~m}$ from the trunk, which corresponded with the zones wetted by the irrigation bulbs and where large numbers of fallen leaves were located.

Defoliation from olives trees infected by the D pathotype was extensive during the late winter to early spring period, being almost nil from trees infected by the ND pathotype. The fallen leaves can be easily dispersed by wind and thus can infest soils free of the pathogen or increase the inoculum density in those being already infested. Both the shorter distance between adjacent trees and higher root density within rows compared with those between trees across rows could have favored the spread of infected leaves to the neighboring tree and therefore contribute to the slightly higher aggregation of $\mathrm{D} V$. dahliae-infected trees within rows and the increase in the patch size (Table 1, Fig. 7). Also, the positive relationship between aggregation of diseased trees and disease incidence is consistent with the hypothesized short distance dispersion of infected, fallen leaves. Nevertheless, those leaves may also be dispersed to longer distances and act as primary inoculum for new disease foci thus increasing the number of patches over time. In our study, new diseased foci of $\mathrm{D} V$. dahliae-infected olives were detected as far as $196 \mathrm{~m}$ from the main patch cluster (Fig. 7).

We believe that dispersal of pathogen inocula in surface water can be considered of lesser importance and restricted to surface rain water because of the use of a uniform, flat plot drip irrigation. Conversely, dispersal of inoculum by human activities including movement of machinery and equipment with infested soil and/or infected fallen leaves mainly through mechanical operations of neighboring infested plots should be considered of importance. This means of dispersal could be responsible for the introduction of the D pathotype into the orchard of the study from a field plot in close proximity that was repeatedly cropped to cotton or vegetable crops susceptible to Verticillium wilt until 2 years prior to the olive planting. This plot is infested with a high inoculum density of D V. dahliae (J. Bejarano-Alcázar, personal communication). The olive orchard and cotton plots are located approximately $100 \mathrm{~m}$ apart in the Agricultural Research Station of the study and share the use of operators, machinery, and equipment that move across paths connecting the two plots. Likely,

TABLE 3. Associations between pairwise combinations of incidence of Verticillium wilt of olive at southern Spain by SADIE association index $\left(X_{k}\right)^{\mathrm{a}}$ among different disease assessment dates

\begin{tabular}{|c|c|c|c|c|c|c|c|c|}
\hline \multirow[b]{3}{*}{ Date of assessment ${ }^{\mathrm{b}}$} & \multicolumn{8}{|c|}{ Date of assessment } \\
\hline & \multicolumn{2}{|c|}{$06 / 14 / 00$} & \multicolumn{2}{|c|}{$06 / 26 / 01$} & \multicolumn{2}{|c|}{$07 / 12 / 02$} & \multicolumn{2}{|c|}{$05 / 28 / 03$} \\
\hline & $X_{k}$ & $P$ & $X_{k}$ & $P$ & $X_{k}$ & $P$ & $X_{k}$ & $P$ \\
\hline $06 / 14 / 00$ & $\ldots$ & $\ldots$ & 0.7498 & $<0.0065$ & 0.5848 & $<0.0065$ & 0.4142 & $<0.0065$ \\
\hline $06 / 26 / 01$ & $\ldots$ & $\ldots$ & $\ldots$ & $\ldots$ & 0.7000 & $<0.0065$ & 0.5444 & $<0.0065$ \\
\hline 07/12/02 & $\ldots$ & $\ldots$ & $\ldots$ & $\ldots$ & $\ldots$ & $\ldots$ & 0.6893 & $<0.0065$ \\
\hline \multicolumn{9}{|l|}{ Nondefoliating pathotype } \\
\hline 07/12/02 & $\ldots$ & $\ldots$ & $\ldots$ & $\ldots$ & $\ldots$ & $\ldots$ & 1 & 0 \\
\hline \multicolumn{9}{|l|}{ Defoliating pathotype } \\
\hline $06 / 14 / 00$ & $\ldots$ & $\ldots$ & 0.6094 & $<0.0001$ & 0.5454 & $<0.0001$ & 0.4352 & $<0.0001$ \\
\hline $06 / 26 / 01$ & $\ldots$ & $\ldots$ & $\ldots$ & $\ldots$ & 0.6469 & $<0.0001$ & 0.5009 & $<0.0001$ \\
\hline $07 / 12 / 02$ & $\ldots$ & $\ldots$ & $\ldots$ & $\ldots$ & $\ldots$ & $\ldots$ & 0.7162 & $<0.0001$ \\
\hline \multicolumn{9}{|l|}{$\begin{array}{l}\text { Nondefoliating vs. } \\
\text { defoliating pathotypes }\end{array}$} \\
\hline
\end{tabular}

${ }^{a} X_{k}$ is the overall level of association between the two Verticillium dahliae pathotypes at each assessment date after correcting for spatial autocorrelation in the expected values through the Dutilleul adjustment.

${ }^{\mathrm{b}}$ Analyses were preformed for all disease assessment dates made at 1-month intervals, however to simplify; only those from disease assessments made at the end of each crop season are shown. 
infested soil from this plot was introduced into the olive orchard some time before the establishment of the olive planting. The inoculum density of the pathotype in the orchard resulting from the incoming infested soil must have been fairly low since one microsclerotia of $\mathrm{D} V$. dahliae per gram of soil or less gave rise to a 24-month incubation period for disease to develop in extremely susceptible 'Picual' plants grown in artificially infested microplots (27), which is about the time (28 months) from planting to appearance of first diseased 'Arbequina' trees in the orchard of the study.

After the introduction of infested soil, mechanical operations performed mainly when preparing the field soil for olive planting might have extended locally the introduced inoculum. Thereafter, the field was managed under no tillage, so that additional movement of soil within the field plot would be of little importance. Further, in early stages of the epidemic (i.e., first two cropping seasons) the spatial distribution of D-infected trees should reflect the spatial distribution of pathogen propagules in soil. Thereafter, additional localized dispersion of the pathogen to neighboring trees must have occurred by means of infected, fallen leaves. This gave rise to an increased number of disease patches, but more importantly an increase of patch size, by infections of neighboring trees and/or coalescence of those previously established (Figs. 7 and 8). Moreover, few pathogen genotypes must have been dispersed across the orchard since the majority (89\%) of D $V$. dahliae isolates from infected olives were of the same genotype (i.e., shared the same MP-PCR fingerprinting profile); and this fingerprinting was identical to that obtained for $V$. dahliae isolates from soil of the nearby plot frequently cropped to cotton. The low percentage $(11 \%)$ of $\mathrm{D}$ isolates belonging to different genotypes may also indicate an external introduction of those isolates in infected trees at the time of the planting as may have occurred for ND isolates.

That root growth might have played some role in the spatiotemporal increase of the disease within the orchard, through an increase in the encounters between root tissues and $V$. dahliae microsclerotia in soil, cannot be disregarded. However, we consider this of minor significance compared with the proposed role of infected, fallen leaves, because of the large amount of inoculum that they provide in close proximity to the newly growing roots (12) and the likely low resident inoculum density in the soil.

In summary, results of this study demonstrated that severe Verticillium wilt epidemics in newly established high tree-density, irrigated olive orchards could occur within a relatively short period of time even in soils without a history of $V$. dahliae. Our results also demonstrate that $V$. dahliae $\mathrm{D}$ and ND pathotypes that infect olives have different modes of dispersion and originate different disease spatial patterns. Infections by the D pathotype are of greater concern because the pathogen can spread rapidly, local as well as over relatively long distances, by windblown infected leaves fallen early and in large numbers from diseased trees. In addition, the different sources of primary inoculum suggested for infections of the trees strengthen the need that care should be taken to avoid both introduction of the pathogen in infected planting material and/or in soil from infested, neighboring fields.

\section{ACKNOWLEDGMENTS}

Research support was provided by grant QLRT-1999-1523 from the European Commission (Framework Programme 5). B. B. Landa is a contract holder of the 'Ramón y Cajal' program of the Ministerio de Educación y Ciencia of Spain. We are grateful to F. Orgaz, IAS-CSIC, and M. Pastor, IFAPA, for facilitating the use of the experimental orchard in the study and assistance for its management. We acknowledge the contribution made by A. Valverde-Corredor early in the preliminary characterization of part of $V$. dahliae isolates. Also, we thank F. Ferrandino for providing the EPISTAT software and L. V. Madden for providing the BBD software. We thank T. C. Paulitz and J. A. Hiemstra for critically reading the manuscript, and the Senior Editor and anonymous reviewers for suggestions and editorial improvements.

\section{LITERATURE CITED}

1. Bassanezi, R. B., Bergamin Filho, A., Amorim, L., Gimenes-Fernandes, N., Gottwald, T. R., and Bové, J. M. 2003. Spatial and temporal analyses of citrus sudden death as a tool to generate hypotheses concerning its etiology. Phytopathology 93:502-512.

2. Bejarano-Alcázar, J., Blanco-López, M. A., Melero-Vara, J., and JiménezDíaz, R. M. 1996. Etiology, importance, and distribution of Verticillium wilt of cotton in southern Spain. Plant Dis. 80:1233-1238.

3. Bejarano-Alcázar, J., and Jiménez-Díaz, R. M. 2000. Analysis of the spatial pattern of Verticillium dahliae in soils of cotton fields. Pages 340342 in: Advances in Verticillium Research and Disease Management. E. C. Tjamos, R. C. Rowe, J. B. Heale, and D. R. Fravel, eds. American Phytopathological Society, St. Paul, MN.

4. Bejarano-Alcázar, J., Melero-Vara, J. M., Blanco-López, M. A., and Jiménez-Díaz, R. M. 1995. Influence of inoculum density of defoliating and nondefoliating pathotypes of Verticillium dahliae on epidemics of Verticillium wilt of cotton in southern Spain. Phytopathology 85:14741481.

5. Bhat, R. G., Smith, R. F., Koike, S. T., Wu, B. M., and Subbarao, K. V. 2003. Characterization of Verticillium dahliae isolates and wilt epidemics of pepper. Plant Dis. 87:789-797.

6. Blanco-López, M. A., Jiménez-Díaz, R. M., and Caballero, J. M. 1984. Symptomatology, incidence and distribution of Verticillium wilt of olive trees in Andalucia. Phytopathol. Mediterr. 23:1-8.

7. Campbell, C. L., and Benson, D. M. 1994. Spatial aspects of the development of root disease epidemics. Pages 195-243 in: Epidemiology and Management of Root Diseases. C. L. Campbell and D. M. Benson, Springer Verlag, Berlin.

8. Collado-Romero, M., Mercado-Blanco, J., Olivares-García, C., ValverdeCorredor, A., and Jiménez-Díaz, R. M. 2006. Molecular variability within and among Verticillium dahliae vegetative compatibility groups determined by fluorescent amplified fragment length polymorphism and polymerase chain reaction markers. Phytopathology 96:485-495.

9. Dallot, S., Gottwald, T., Labonne, G., and Quiot, J.-B. 2003. Spatial pattern analysis of Sharka disease (Plum pox virus strain $\mathrm{M}$ ) in peach orchards of southern France. Phytopathology 93:1543-1552.

10. Easton, G. D., Nagle, M. E., and Bailey, D. L. 1969. A method of estimating Verticillium albo-atrum propagules in field soil and irrigation water. Phytopathology 59:1171-1172.

11. Elena, K., and Paplomatas, E. J. 2001. The defoliating strain of Verticillium dahliae on cotton: First report for Greece. (Abstr.) Phytopathol. Mediterr. 40:70.

12. Fernández, J. E., Moreno, F., Cabrera, F., Arrue, J. L., and Martín-Aranda, J. 1991. Drip irrigation, soil characteristics and the root distribution and root activity of olive trees. Plant Soil 133:239-251.

13. Ferrandino, F. J. 2005. The explicit dependence of quadrat variance on the ratio of clump size to quadrat size. Phytopathology 95:452-462.

14. Gilligan, C. A. 1983. A test for randomness by soilborne pathogens. Phytopathology 73:300-303.

15. Gilligan, C. A. 1994. Temporal aspects of the development of root disease epidemics. Pages 149-193 in: Epidemiology and Management of Root Diseases. C. L. Campbell and D. M. Benson, eds. Springer-Verlag, Heidelberg, Germany.

16. Gottwald, T. R., Garnsey, S. M., and Borbón, J. 1998. Increase and patterns of spread of citrus tristeza virus infections in Costa Rica and the Dominican Republic in the presence of the brown citrus aphid, Toxoptera citricida. Phytopathology 88:621-636.

17. Green, R. J. Jr. 1969. Survival and inoculum potential of conidia and microsclerotia of Verticillium albo-atrum in soil. Phytopathology 59:874876.

18. Harris, D. C., and Yang, J. R. 1996. The relationships between the amount of Verticillium dahliae in soil and the incidence of strawberry wilt as a basis for disease risk prediction. Plant Pathol. 45:106-114.

19. Hau, B., Amorin, L., and Bergamin Filho, A. 1993. Mathematical functions to describe progress curves of double sigmoid pattern. Phytopathology 83:928-932.

20. Hiemstra, J. 2000. Petioles from infected trees spread Verticillium dahliae. Pages 137-139 in: Advances in Verticllium Research and Disease Management. E. C. Tjamos, R. C. Rowe, J. B. Heale, and D. Fravel, eds. The American Phytopathological Society, St. Paul, MN.

21. Hughes, G., and Madden, L. V. 1992. Aggregation and incidence of disease. Plant Pathol. 41:657-660.

22. Hughes, G., and Madden, L. V. 1993. Using the beta-binomial distribution to describe aggregated pattern of disease incidence. Phytopathology 83:759-763. 
23. Jiménez-Díaz, R. M., Tjamos, E. C., and Cirulli, M. 1998. Verticillium wilt of major tree hosts: Olive. Pages 13-16 in: A Compendium of Verticillium Wilt in Tree Species. J. A. Hiemstra, D. C. Harris, eds., Ponsen and Looijen, Wageningen, The Netherlands.

24. Johnson, K. B., Apple, J. D., and Powelson, M. L. 1988. Spatial patterns of Verticillium dahliae propagules in potato field soils of Oregon's Columbia Basin. Plant Dis. 72:484-488.

25. Korolev, N., Katan, J., and Katan, T. 2000. Vegetative compatibility groups of Verticillium dahliae in Israel: Their distribution and association with pathogenicity. Phytopathology 90:529-536.

26. Levin, A. G., Lavee, S., and Tsror (Lahkim), L. 2003. Epidemiology of Verticillium dahliae on olive (cv. Picual) and its effect on yield under saline conditions. Plant Pathol. 52:212-218.

27. López-Escudero, F. J., and Blanco-López, M. A. 2007. Relationship between inoculum density of Verticillium dahliae and the progress of Verticillium wilt of olive. Plant Dis. 91:1372-1378.

28. López-Escudero, F. J., del Río, C., Caballero, J. M., and Blanco-López, M. A. 2004. Evaluation of olive cultivars for resistance to Verticillium dahliae. Eur. J. Plant Pathol. 110:79-85.

29. Ma, Z., Luo, Y., and Michailides, T. J. 2004. Spatiotemporal changes in the population structure of Botryosphaeria dothidea from California pistachio orchards. Phytopathology 94:326-332.

30. Madden, L. V., and Hughes, G. 1994. BBD-Computer software for fitting the beta-binomial distribution to disease incidence data. Plant Dis. 78:536-540.

31. Madden, L. V., and Hughes, G. 1995. Plant disease incidence: Distributions, heterogeneity, and temporal analysis. Annu. Rev. Phytopathol. 33:529-564.

32. Madden, L. V., Louie, R., Abt, J. J., and Knoke, J. K. 1982. Evaluation of tests for randomness of infected plants. Phytopathology 72:195-198.

33. Mercado-Blanco, J., Rodríguez-Jurado, D., Parrilla-Araujo, S., and Jiménez-Díaz, R. M. 2003. Simultaneous detection of the defoliating and nondefoliating Verticillium dahliae pathotypes in infected olive plants by duplex, nested polymerase chain reaction. Plant Dis. 87:1487-1494.

34. Paplomatas, E. J., Bassett, D. M., Broome, J. C., and DeVay, J. E. 1992. Incidence of Verticillium wilt and yield losses of cotton cultivars (Gossypium hirsutum) based on soil inoculum density of Verticillium dahliae. Phytopathology 82:1417-1420.

35. Pegg, G. F., and Brady, B. L. 2002. Verticillium Wilts. CAB International, Wallingford, UK.

36. Perry, J. N., Winder, L., Holland, J. M., and Alston, R. D. 1999. Red-blue plots for detecting clusters in count data. Ecol. Lett. 2:106-113.

37. Pethybridge, S. J., Esker, P., Hay, F., Wilson, C., and Nutter, F. W., Jr. 2005. Spatiotemporal description of epidemics caused by Phoma ligulicola in Tasmanian pyrethrum fields. Phytopathology 95:648-658.

38. Ridout, M. S., and Xu, X.-M. 2000. Relationships between several quadrat-based statistical measures used to characterize spatial aspects of data on disease incidence. Phytopathology 90:568-575.

39. Rijkers, A. J. M., Hiemstra, J. A., and Bollen, G. J. 1992. Formation of microsclerotia of Verticillium dahliae in petioles of infected ash trees. Neth. J. Plant Pathol. 98:261-264
40. Rodríguez-Jurado, D., Blanco-López, M. A., Rapoport, H. E., and Jiménez-Díaz, R. M. 1993. Present status of verticillium wilt of olive in Andalucia (southern Spain). Bulletin OEPP/EPPO Bulletin 23:513-516

41. Rodríguez-Jurado, D., Porras-Alonso, R., Trapero-Casas, J. L., and Jiménez-Díaz, R. M. 2002. Potencial de las hojas de olivo caídas tras la infección por el patotipo defoliante de Verticillium dahliae como fuente de inóculo en las epidemias de Verticilosis. Page 228 in: Resúmenes, XI Congreso de la Sociedad Española de Fitopatología, SEF-IFAPA, Almería, Spain.

42. Sánchez-Hernández, M. E., Ruiz-Dávila, A., Pérez de Algaba, A., BlancoLópez, M. A., and Trapero-Casas, A. 1998. Occurrence and etiology of death of young olive trees in southern Spain. Eur. J. Plant Pathol. 104:347-357.

43. Schnathorst, W. C., and Sibbett, G. S. 1971. The relation of strain of Verticillium albo-atrum to severity of Verticillium wilt in Gossypium hirsutum and Olea europaea in California. Plant Dis. Rep. 9:780-782.

44. Scott, J. B., Hay, C. R., Scott, J. B., Hay, F. S., Wilson, C. R., Cotterill, P. J., and Fist, A. J. 2003. Spatiotemporal analysis of epiphytotics of downy mildew of oilseed poppy in Tasmania, Australia. Phytopathology 93:752757.

45. Talboys, P. W. 1960. A culture medium aiding the identification of Verticillium albo-atrum and V. dahliae. Plant Pathol. 9:57-58.

46. Termorshuizen, A. J., Davis, J. R., Gort, G., Harris, D. C., Huisman, O. C., Lazarovits, G., Locke, T., Melero Vara, J. M., Mol, L., Paplomatas, E. J., Platt, H. W., Powelson, M., Rouse, D. I., Rowe, R. C., and Tsror, L. 1998. Interlaboratory comparison of methods to quantify microsclerotia of Verticillium dahliae in soil. Appl. Environ. Microbiol. 64:3846-3853.

47. Thanassoulopoulos, C. C. 1993. Spread of Verticillium wilt by nursery plants in olives grows in the Halkidiki area (Greece). Bulletin OEPP/EPPO Bulletin 23:517-520.

48. Thanassoulopoulos, C. C., Biris, D. A., and Tjamos, E. C. 1981. Dissemination of Verticillium propagules in olive orchards by irrigation water. Pages 52-53 in: Proceedings of the 5th Congress of the Mediterranean Phytopathological Union, Patras, Greece.

49. Tjamos, E. C., and Botseas, D. 1987. Occurrence of Verticillium dahliae in leaves of Verticillium-wilted olive trees. Can. J. Plant Pathol. 9:86.

50. Tjamos, E. C., and Tsougriani, H. 1990. Formation of Verticillium dahliae microsclerotia in partially disintegrated leaves of Verticillium wilt affected olive trees. Page 20 in: 5th International Verticillium Symposium Book of Abstracts, Leningrad.

51. Winder, L., Alexander, C. J., Holland, J. M., Woolley, C., and Perry, J. N. 2001. Modeling the spatio-temporal response of predation to transient prey patches in the field. Ecol. Lett. 4:568-576.

52. Xiao, C. L., Hao, J. J., and Subbarao, K. V. 1997. Spatial patterns of microsclerotia of Verticillium dahliae in soil and Verticillium wilt of cauliflower. Phytopathology 87:325-331.

53. Xu, X.-M., and Madden, L. V. 2003. Considerations for the use of SADIE statistics to quantify spatial patterns. Ecography 26:821-830.

54. Xu, X.-M., and Madden, L. V. 2004. Use of SADIE statistics to study spatial dynamics of plant disease epidemics. Plant Pathol. 53:38-49. 